\title{
Pubertal Testosterone Programs Adult Behavioral Adaptations to Sexual Experience through Infralimbic Cortex $\Delta$ FosB
}

\author{
Kayla C. De Lorme, ${ }^{1,4}$ Nancy A. Staffend-Michael, ${ }^{2}$ Sarah C. Simmons, ${ }^{2}$ Alfred J. Robison, ${ }^{2,3}$ and \\ (1) Cheryl L. Sisk ${ }^{1,2}$
}

https://doi.org/10.1523/ENEURO.0176-19.2019

${ }^{1}$ Department of Psychology, Michigan State University, East Lansing, MI 48824, ${ }^{2}$ Neuroscience Program, Michigan State University, East Lansing, MI 48824, ${ }^{3}$ Department of Physiology, Michigan State University, East Lansing, MI 48824, and ${ }^{4}$ Department of Psychological Science, Gustavus Adolphus College, Saint Peter, MN 56082

\begin{abstract}
Acquisition of social proficiency entails behavioral adaptations to social experience, including both behavioral flexibility and inhibition of behaviors inappropriate in specific social contexts. Here, we investigated the contributions of testosterone and $\Delta \mathrm{FosB}$, a transcription factor linked to experience-dependent neural plasticity, to the adolescent maturation of social proficiency in male-female social interactions. To determine whether pubertal testosterone organizes circuits underlying social proficiency, we first compared behavioral adaptations to sexual experience in male Syrian hamsters that were deprived of testosterone during puberty (prepubertal castration; NoT@P) to those of males deprived of testosterone for an equivalent period of time in adulthood (postpubertal castration; T@P). All males were given testosterone replacement in adulthood for two weeks before sexual behavior testing, where males were allowed to interact with a receptive female once per week for five consecutive weeks. T@P males showed the expected decrease in ectopic (mis-directed) mounts with sexual experience, whereas NoT@P males did not. In addition, sexual experience induced FosB gene products expression in the infralimbic cortex (IL) in T@P, but not NoT@P, males. Overexpression of $\Delta$ FosB via an adeno-associated viral (AAV) vector in the IL of NoT@P males prior to sexual behavior testing was sufficient to produce a behavioral phenotype similar to that of experienced T@P males. Finally, overexpression of $\Delta$ FosB in IL increased the density of immature spines on IL dendrites. Our findings provide evidence that social proficiency acquired through sexual experience is organized by pubertal testosterone through the regulation of $\Delta \mathrm{FosB}$ in the IL, possibly through increasing synaptic lability.
\end{abstract}

Key words: $\Delta$ FosB; ectopic mounts; medial prefrontal cortex; puberty; social proficiency; testosterone

\section{Significance Statement}

Social proficiency is the ability to make experience-dependent behavioral adaptations that enhance the success of subsequent social interactions. In male rodents, social proficiency in adulthood is programmed by the pubertal rise in testosterone, but neuroendocrine mechanisms underlying this behavioral plasticity are not understood. We show that pubertal testosterone is necessary for both sexual proficiency and experience-dependent induction of $\triangle \mathrm{FosB}$ in the infralimbic (IL) medial prefrontal cortex (mPfC) in adulthood. Furthermore, overexpression of $\Delta \mathrm{FosB}$ in the IL increases immature dendritic spines on IL neurons and is sufficient to restore a socially proficient phenotype in males that lacked testosterone during puberty. Hormonal programming of experience-dependent regulation of prefrontal $\Delta F o s B$ is a novel mechanism of adolescent development of behavioral and neural plasticity in adulthood. 


\section{Introduction}

A vital aspect of adolescent development is the acquisition of social behaviors and skills that prepare an individual for successful adult social interactions and promote evolutionary fitness. During adolescence, the primary social sphere transitions from family to peers, resulting in new social experiences and competencies (Nelson et al., 2005). Social proficiency is the ability of an individual to make experience-dependent behavioral adaptations that enhance the success of subsequent social interactions, and this proficiency involves behavioral flexibility and inhibition of maladaptive behaviors. Adolescent maturation of behavioral inhibition and social proficiency necessarily involves circuits underlying executive control of social motivation and learning (De Lorme et al., 2013), but the neural and endocrine mechanisms of this developmental change are largely unexplored; the present experiments were designed to identify these potential mechanisms.

Many of the behavioral changes related to the adolescent maturation of social proficiency have been attributed to puberty, which defines the onset of adolescence and is characterized by an increase in gonadal hormone secretion as reproductive maturation begins. The single-most important social interaction for evolutionary fitness is sexual behavior that leads to the production of offspring. Adolescent maturation of male sexual behavior is achieved in part through organizational effects of testosterone on the developing brain to program sexual proficiency, as shown in studies using male Syrian hamsters. For example, during a first sexual encounter with a receptive female, sexually naive adult male hamsters typically display a high rate of ectopic (mis-directed) mounts in addition to vaginally oriented mounts. With sexual experience, however, the number of ectopic mounts decreases, thereby improving sexual proficiency and reproductive success (Schulz and Sisk, 2006). Notably, the acquisition of sexual proficiency is not observed in adult hamsters deprived of testosterone during puberty via prepubertal castration; such males continue to show high rates of ectopic mounts even after repeated sexual encounters (Schulz and Sisk, 2006; De Lorme and Sisk, 2016). These data suggest that testosterone programs

Received May 10, 2019; accepted May 18, 2019; First published May 28, 2019. The authors declare no competing financial interests.

Author contributions: K.C.D., N.A.S.-M., A.J.R., and C.L.S. designed research; K.C.D., N.A.S.-M., S.C.S., and A.J.R. performed research; K.C.D. and A.J.R. analyzed data; K.C.D., A.J.R., and C.L.S. wrote the paper.

This work was supported by National Institutes of Health Grants R01 MH068764 (to C.L.S.), T32 MH0700343 (to K.C.D.), R01 MH111694 (to A.J.R.), R01 DA040621 (to A.J.R.), and F31 DA042502 (to S.C.S.).

Acknowledgements: We thank Dr. Margaret Mohr, Dr. Elaine Sinclair, Dr. Andrew Kneynsberg, and Jane Venier for their contributions to experimental design, surgical procedures, and data collection.

Correspondence should be addressed to Kayla C. De Lorme at kdelorme@gustavus.edu

https://doi.org/10.1523/ENEURO.0176-19.2019

Copyright (C) 2019 De Lorme et al.

This is an open-access article distributed under the terms of the Creative Commons Attribution 4.0 International license, which permits unrestricted use, distribution and reproduction in any medium provided that the original work is properly attributed. social proficiency by organizing neural circuitry involved in behavioral inhibition.

The medial prefrontal cortex ( $\mathrm{mPfC}$ ) and nucleus accumbens (NAc) are key components of the neural circuitry that regulates motivated behaviors. The $\mathrm{mPfC}$ is involved in behavioral flexibility and inhibition, whereas the NAc is critical for processing and evaluating social information and then generating a behavioral response (Sesack and Grace, 2010; Euston et al., 2012). Sexual experience induces long-term expression of the transcription factor $\triangle$ FosB within both the $\mathrm{mPfC}$ and NAc of male and female rodents, and experimental overexpression of $\Delta$ FosB in the NAc of sexually naive female and male rodents increases sexual performance and motivation (Wallace et al., 2008; Hedges et al., 2009; Pitchers et al., 2010). Therefore, $\triangle$ FosB induction within the $\mathrm{mPfC}$ and NAc appears to be an element of the restructuring of neural circuits that underlie long-term behavioral adaptations with sexual experience. One possible mechanism by which the induction of $\Delta$ FosB mediates experience-dependent plasticity is through the formation of immature dendritic spines, as $\Delta$ FosB overexpression in the NAc increases immature dendritic spines (Grueter et al., 2013; Robison et al., 2013; Eagle et al., 2015). Thus, $\Delta$ FosB may regulate behavioral plasticity by modulating transcription of downstream target genes related to synaptic plasticity.

Here, we investigated the neural mechanisms by which pubertal testosterone programs sexual proficiency in adulthood. First, to determine if pubertal testosterone affects regulation of $\Delta F o s B$, the effects of sexual experience on $\Delta$ FosB expression in the $\mathrm{mPfC}$ and NAc were compared in male hamsters that underwent adolescent development in either the presence or absence of testosterone during puberty. Next, to link $\Delta$ FosB with behavioral flexibility and inhibition, we determined whether overexpression of $\Delta$ FosB in the infralimbic cortex (IL) of the $\mathrm{mPfC}$ is sufficient to restore sexual proficiency in males that were deprived of testosterone during puberty. Finally, we asked whether sexual experience or overexpression of $\Delta$ FosB in the IL of sexually naive males induce similar changes in IL dendritic spines. We discovered that pubertal testosterone programs behavioral adaptability through the regulation of $\Delta \mathrm{FosB}$ in the $\mathrm{IL}$, and our data also suggest that $\Delta$ FosB in the IL may exert its behavioral effects through changes in glutamatergic synapse formation and/or stability.

\section{Materials and Methods}

\section{General methods \\ Animals}

To exclude age at shipment as a potentially confounding variable, and to ensure that postweaning housing conditions were similar for all experimental subjects in experiments 1 and 2, gonad-intact weanling [postnatal day $(P) 21-P 26]$ male Syrian hamsters were ordered from Harlan Laboratories (Madison, WI). In addition, so that prepubertal and postpubertal gonadectomies, stereotaxic injections, behavioral testing, and tissue collection could be performed at the same time for all groups in experiments 1 and 2 , the males that were gonadectomized 


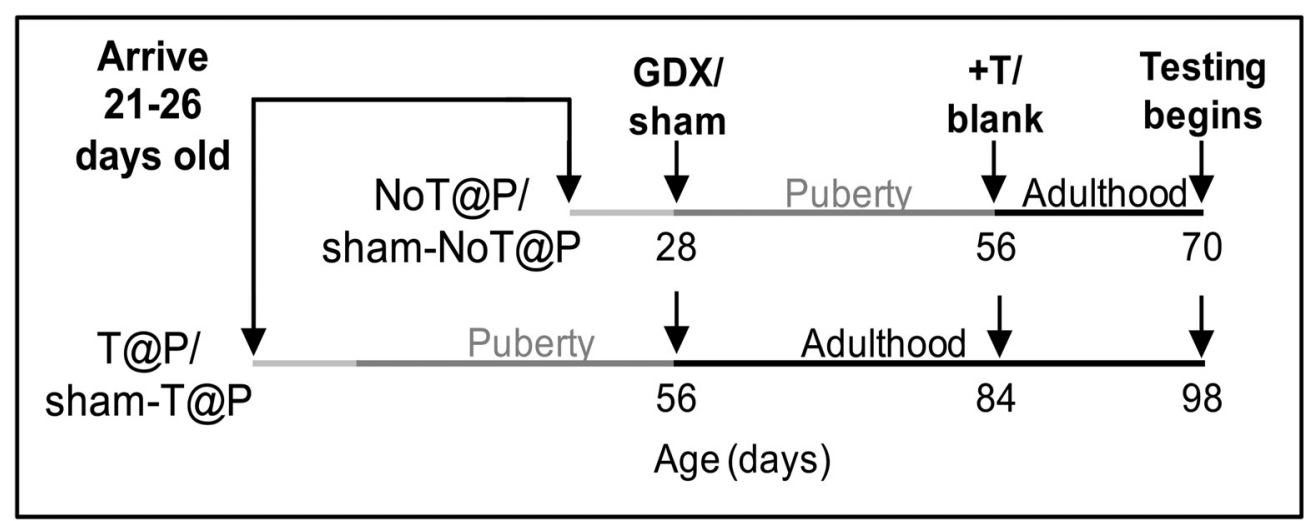

Figure 1. Experimental design of experiment 1. T@P and sham-T@P males arrived four weeks before NoT@P and sham-NoT@P males to control for the age of shipping and environment during puberty. Two to $7 \mathrm{~d}$ after the NoT@P and sham-NoT@P arrived, males were either GDX or sham-GDX during adulthood (P56; T@P and sham-T@P) or prepubertally (P28; NoT@P and sham-NoT@P). Four weeks later, T@P and NoT@P males received testosterone (T)-filled capsules and sham males received empty (blank) capsules of the same size. Sexual behavior testing began two weeks later.

(GDX) prepubertally were shipped and received four weeks later than males that were GDX postpubertally (Gonadectomy described below; Fig. 1). For experiment 3 , sexually naive, gonad-intact adult male hamsters were ordered from Harlan. For all experiments, hamsters were individually housed in clear polycarbonate cages $(30.5 \times$ $10.2 \times 20.3 \mathrm{~cm}$ ) with ad libitum access to food and water in a 14/10 h light/dark cycle (lights out at 2 P.M.) on arrival. Sample sizes and experimental manipulations are described for each experiment below. Ovariectomized, sexually experienced female Syrian hamsters (four to seven months of age) from our colony (also originally obtained from Harlan) were used as stimulus animals in behavioral tests. All animals were treated in accordance with the National Institutes of Health Guide for the Care and Use of Laboratory Animals and protocols were approved by the Michigan State University Institutional Animal Care and Use Committee.

\section{Gonadectomy}

Gonadectomies were performed on male hamsters under isoflurane anesthesia and aseptic conditions. Before the procedure, ketoprofen analgesic ( $5 \mathrm{mg} / \mathrm{kg}$, s.c.) was administered to each male. For the surgery, a bilateral scrotal incision 8-10 $\mathrm{mm}$ in length was made, the testes were then gently pulled through the incision, and the testicular veins and arteries were tied with suture silk (3-0) before removal of the testes. For prepubertal animals, testes were removed via cauterization of the testicular veins and arteries. For sham surgeries in experiment 1 , a bilateral scrotal incision $8-10 \mathrm{~mm}$ in length was made, the testes were then gently pulled through the incision, and then placed back into the incision. After removal of the testes (gonadectomy) or replacement of testes back into the incision (sham surgery), the incisions were closed with suture silk (5-0).

\section{Testosterone replacement}

Two SILASTIC pellets ( 13 and $5 \mathrm{~mm}$ in length with $4 \mathrm{~mm}$ of sealing glue on both ends; inner diameter $1.98 \mathrm{~mm}$; outer diameter $3.18 \mathrm{~mm}$ ) that contained either testosterone or nothing were inserted subcutaneously through a 5-mm incision made on the dorsal midline between the scapulae of the animal while anesthetized with isoflurane. The pellets are constructed by loading SILASTIC tubing with powdered testosterone (or left empty) and sealing each end of the tube with surgical grade adhesive.

\section{Stimulus females}

Behavioral receptivity was induced in ovariectomized female hamsters by treatment with estradiol benzoate (10 $\mu \mathrm{g}$ in $0.05-\mathrm{ml}$ sesame oil, s.c.) and progesterone (500 $\mu \mathrm{g}$ in $0.1-\mathrm{ml}$ sesame oil, s.c.) 52 and $4-5 \mathrm{~h}$, respectively, before use in sexual behavior tests with males. Each receptive female was used only once per sexual behavior test and was never paired with the same male more than once throughout the experiments.

\section{Sexual behavior testing}

In all experiments, testing began $1 \mathrm{~h}$ into the dark phase of the light-dark cycle under dim red light. Following a 2-min acclimation period in a clean large glass aquarium, each male was allowed to interact with a receptive female until the male achieved the sexual behavior criteria for that trial or after 30 min had passed, whichever came first. Previous experiments showed that during fixed-time tests, males deprived of testosterone during puberty achieve fewer intromissions and ejaculations than males deprived after puberty, and consequently, less sensory feedback that is potentially important for behavioral adaptations (Schulz et al., 2004; Schulz and Sisk, 2006). To address this possible confound, instead of absolute amount of time with the female, sexual behavior was equated for all males to ensure that any behavioral differences between groups were not due to different sensory experience. The behavioral criteria that ended each trial were: one ejaculation for trial 1, one ejaculation plus two intromissions for trial 2, two ejaculations for trial 3, one ejaculation plus two intromissions for trial 4 , and one ejaculation for trial 5 . The behavioral criteria were varied because we found in a previous study that when the same criterion was applied for each sexual behavioral test (achieving five intromissions) both gonad-intact and T@P male hamsters would decrease their sexual behavior after 
trial 3 (De Lorme and Sisk, 2016). Behavior testing was conducted once a week for five consecutive weeks (one of the five above-described trials per week). Males were excluded from further study if they did not meet the behavioral criteria in at least three out of the first four trials. Behavior during each trial was digitally recorded for later quantification.

\section{Sexual behavior quantification}

The behaviors investigated for experiments 1 and 2 were: rate (instances/min) of ectopic mounts (male grips female tightly and displays fast thrusting, but the mount is not vaginally oriented), latency to mount (male orients himself on the female's hind flanks, grips her tightly with his forepaws, and displays fast thrusts), latency to intromit (male is vaginally-oriented and makes a long-lasting thrust resulting in vaginal penetration), latency to ejaculate (occurring after a series of intromissions followed by the male self-grooming and showing no sexual interest in the female for at least $20 \mathrm{~s}$ ), and number of intromissions to reach ejaculation. Ejaculation latency and intromissions to ejaculate reflect sexual performance, whereas latencies to mount or intromit are measures of sexual motivation (Hull et al., 2002). Latencies to mount and intromit were timed from the moment the female was introduced to the male in the aquarium, and latency to ejaculate was defined as the amount of time that passed between the first intromission and ejaculation. Rate of ectopic mounting was used because males reached behavioral criteria to end the trial within varying times; rate was calculated by dividing the frequency of ectopic mounts displayed by the total test time per male per trial. All behavioral statistical analyses were performed using IBM SPSS software (version 19).

\section{Experiment 1: determine the effects of pubertal testosterone on sexual proficiency and $\Delta$ Fos $B$ expression in the $\mathrm{MPfC}$ and NAc \\ Animals (Fig. 1)}

This experiment was conducted in three consecutive cohorts, with all experimental and control groups represented in each cohort. A total of 109 male hamsters were used in the experiment. Four to five weeks after the first group of weanling males arrived and 2-7 $d$ after the second group of weanling males arrived (see above in the General methods Animals section for age at shipping), half of the first group (now adults, P56) and half of the second group (prepubertal, P28) males were either GDX (T@P and NoT@P, respectively) or received sham surgeries (sham-T@P and sham-NoT@P, respectively). The sham groups were used as age-matched methodological controls to confirm that behavioral differences found between T@P and NoT@P males were due to the presence or absence of testosterone during puberty, and not to age at the time of surgery or at the time of behavior testing. Four weeks after surgery, when all males were in adulthood, the T@P and NoT@P males received two testosterone-filled capsules and the sham-T@P and sham-NoT@P males received blank capsules of matched size. Two weeks later, approximately half of the males from each group began sexual behavior testing, while the other half of each group remained sexually naive. The sexually naive males were placed in an empty aquarium for 5 min before sexual behavior testing began for the sexually experienced males. This was done to ensure that the sexually naive males were not exposed to female pheromones that could have been present in the behavior testing room following sexual behavior testing, and eliminated any confound of handling and being placed in an aquarium, each of which could potentially influence the expression of $\Delta$ FosB in brain regions of interest. Thus, this design yielded eight experimental groups: (1) naive T@P, (2) experienced T@P, (3) naive NoT@P, (4) experienced NoT@P, (5) naive sham-T@P, (6) experienced sham-T@P, (7) naive sham-NoT@P, and (8) experienced shamNoT@P.

\section{Behavioral outliers and sample sizes}

For each behavior, a box-plot using stem-and-leaf descriptives was used to identify the extreme data points within each experimental group. Dixon's Q-test was then used to determine if the extreme was a single statistical outlier. If the extreme was identified as an outlier for any behavior, the data for that animal were taken out of the analysis. One T@P male was an extreme high outlier for intromissions to ejaculation after sexual experience in experiment 1. Final sample sizes for each behavior analyzed are provided in the respective figures or figure legends.

\section{Sexual behavior statistical analyses}

Sexual behavior was analyzed using multilevel modeling (MLM), which provides an integrated assessment of experimental group (T@P, NoT@P) and/or sexual experience (trial 1: naive vs trial 5: experienced) on the measures of behavior described above in Sexual behavior quantification. The model treated the animal as the upper-level sampling unit and sexual experience as the lower-level sampling unit. Experimental groups (between-subjects variable) and sexual experience (trials 1 and 5 , within-subject variable) were independent variables. The error structure was modeled to impose the traditional homoscedasticity assumption used in ANOVA. MLM provides a more powerful analysis than a traditional repeated measures ANOVA because it integrates non-independence between samples from the same subject in the model, and allows unequal sample sizes within the repeated measures. Analyses were performed separately for experimental and sham groups; $p \leq 0.05$ was considered significant.

\section{Tissue collection}

Twenty-four hours after the final behavior test, 64 males ( $n=8$ per group, randomly chosen) were deeply anesthetized with an overdose of sodium pentobarbital (150 $\mathrm{mg} / \mathrm{kg}$, i.p.). The pan-FosB primary antibody used here for immunohistochemistry (rabbit $\alpha$-FosB, sc-48 Santa Cruz Biotechnology) detects both FosB and $\Delta$ FosB; however, previous studies have confirmed that most full-length FosB is degraded within 18-24 h after stimulus (in this case either sexual behavior or being placed in an empty aquarium). Thus, the FosB-immunoreactive (-ir) cells are specifically enriched for $\Delta$ FosB when examined at the chosen time of $24 \mathrm{~h}$ relative to the behavioral manipulation 
Table 1. Concentrations of plasma testosterone

\begin{tabular}{lcc}
\hline \multirow{2}{*}{ Group } & \multicolumn{2}{c}{ Plasma testosterone $(\mathrm{ng} / \mathrm{ml})$} \\
& \multicolumn{2}{c}{ Sexual experience } \\
TaP & $2.77 \pm 1.01$ & Experienced \\
NoT@P & $2.77 \pm 1.21$ & $3.54 \pm 1.66$ \\
Sham-T@P & $1.71 \pm 0.72$ & $3.68 \pm 1.30$ \\
Sham-NoT@P & $1.67 \pm 0.88$ & $2.59 \pm 0.78$ \\
& \multicolumn{3}{c}{$2.57 \pm 0.72$} \\
\hline
\end{tabular}

(Perrotti et al., 2004, 2005, 2008; Wallace et al., 2008; Pitchers et al., 2010). Blood was collected via cardiac puncture, and the animals were perfused with $100 \mathrm{ml}$ of buffered saline rinse and $150 \mathrm{ml}$ of $4 \%$ paraformaldehyde. Brains were collected, postfixed overnight in $4 \%$ paraformaldehyde, and then stored in $20 \%$ sucrose until sectioning. Sections were cut $(40 \mu \mathrm{m})$ into four coronal series using a cryostat and stored in cryoprotectant at $-20^{\circ} \mathrm{C}$ until staining; one series was used for $\Delta$ FosB immunohistochemistry to identify, trace, and count cells in the cingulate (Cg1), prelimbic (PrL), and IL cortices of the $\mathrm{mPfC}$ and shell and core of NAc ( $\triangle$ FosB immunohistochemistry described below).

\section{Radioimmunoassay}

In addition to cardiac blood collection from hamsters used for $\Delta$ FosB immunohistochemistry (described above in Tissue collection), trunk blood was collected from the rest of the hamsters ( $n=5-7$ per group), which were not perfused, via rapid decapitation $24 \mathrm{~h}$ after the final behavior test. Plasma from both blood collections was used to determine testosterone concentrations by radioimmunoassay. Plasma concentrations of testosterone were determined from duplicate $50-\mu$ l samples in a single assay using the Coat-A-Count Total Testosterone kit (Diagnostic Products). The intra-assay coefficient of variance was $3.5 \%$, and the minimum limit of detectability was 0.12 $\mathrm{ng} / \mathrm{ml}$. All sexually naive and sexually experienced males within each experimental group had adult physiologic concentrations of circulating testosterone (Table 1).

\section{$\triangle$ FosB immunohistochemistry}

Free floating sections were first rinsed 4 times for $5 \mathrm{~min}$ with $0.05 \mathrm{M}$ Tris-buffered saline (TBS; $\mathrm{pH}$ 7.6) to remove cryoprotectant, and subsequently rinsed three times for 5 min with TBS between all incubations with reagents. Sections were exposed to $0.1 \%$ hydrogen peroxide for $10 \mathrm{~min}$ at room temperature to destroy endogenous peroxidases. The sections were then blocked in TBS containing 20\% normal goat serum (NGS) and $0.3 \%$ Triton X-100 for 60 min. Sections were then incubated overnight at $4^{\circ} \mathrm{C}$ in $2 \%$ NGS and $0.3 \%$ Triton $\mathrm{X}-100$ and the pan-FosB rabbit polyclonal antibody (1:10,000 dilution for a final concentration of $0.02 \mu \mathrm{g} / \mathrm{ml}$; sc-48 Santa Cruz Biotechnology). After primary antibody incubation, the sections were washed in TBS, and then incubated for $1 \mathrm{~h}$ in goat antirabbit horseradish peroxidase-conjugated secondary antibody (1:500 dilution) containing 2\% NGS and $0.3 \%$ Triton X-100 in TBS. Then, the sections were incubated in Vectastain $A B C$ Elite kit (Vector) for $1 \mathrm{~h}$ at room temperature before visualizing the immunoreactivity with diaminobenzidine (DAB; $0.5 \mathrm{mg} / \mathrm{ml}$ plus $\mathrm{NiCl}$ with $0.025 \%$
$\mathrm{H}_{2} \mathrm{O}_{2}$ ). The sections were rinsed in TBS four times before mounting them onto glass slides. The mounted sections were then put through a series of ethanols and xylene before coverslipping.

\section{Immunohistochemistry analysis}

The number of $\Delta$ FosB-ir cells was quantified in 3 anatomically matched sections for both $\mathrm{mPfC}$ and NAc. For the $\mathrm{mPfC}$, a $450 \times 450-\mu \mathrm{m}$ box was placed in each subregion $(\mathrm{Cg} 1, \mathrm{Prl}, \mathrm{IL})$ relative to brain midline and corpus callosum landmarks, and for the NAc, two $250 \times$ $250-\mu \mathrm{m}$ boxes were placed in the NAc core and a $250 \times$ $250-\mu \mathrm{m}$ box in the NAc shell relative to anterior commissure and lateral ventricle. The Morin and Wood (2001) hamster atlas was also used as a reference. Box placements were determined bilaterally under a $4 \times$ objective.

Cell counts were made within each contour by an experimenter blind to treatment group with an UPlanSApo $40 \times(0.9 N A)$ objective. Cells were considered $\Delta$ FosB-ir if they had a distinct nucleus with visible puncta stained opaque, dark purple-blue; cells that had translucent, lighter stained nuclei were not counted. Sample images of stained cells were also used as a guide to determine which cells met the criteria described above. All analyses were performed on an Olympus BX51 microscope under brightfield illumination using Neurolucida (version 9; Microbrightfield). The number of $\Delta$ FosB-ir cells from the three tissue sections per subregion per hamster was used in statistical analysis (described below).

\section{$\Delta$ FosB-ir expression statistical analysis}

To provide an integrated assessment of pubertal testosterone and sexual experience on $\triangle \mathrm{FosB}$-ir expression within the $\mathrm{MPfC}$ and NAc, MLM was used. For the analysis, the model treated the animal as the upper-level sampling unit and tissue section as the lower-level sampling unit, with pubertal testosterone and sexual experience as independent variables and $\Delta$ FosB-ir cell number as the dependent variable. Interactions were followed up by MLMs within a subset of animals, as appropriate. All statistical analyses were performed using IBM SPSS software (version 19). Analysis was performed separately for experimental and sham groups; $p \leq 0.05$ was considered significant. Due to poor tissue quality for some males, the sample sizes varied between groups of animals. Final sample sizes for each brain region are provided in the data figures.

\section{Experiment 2: determine whether overexpression of $\Delta$ FosB in the IL is sufficient to restore sexual proficiency in NoT@P males}

Experiment 1 showed that the absence of testosterone during puberty impaired sexual proficiency: NoT@P males continued to show high rates of ectopic mounts even after sexual experience. In addition, sexual experience led to an increase in $\triangle$ FosB expression in the IL $\mathrm{mPfC}$ and $\mathrm{NAc}$ core only in T@P males. Experiment 2 was designed to probe the role of $\Delta \mathrm{FosB}$ in sexual proficiency by asking whether overexpression of $\Delta \mathrm{FosB}$ in the IL of NoT@P males is sufficient to instate sexual proficiency. We chose to overexpress $\Delta$ FosB in the IL instead of NAc core because the impairment in sexual proficiency seen in 
NoT@P males appears to be related to impairment in behavioral inhibition, which is more closely linked to IL function than to NAc core function (Vertes, 2006; Euston et al., 2012).

\section{Animals}

Thirty-four male hamsters were used for this experiment; they arrived as gonad-intact weanlings in two groups four weeks apart, as in experiment 1. Four to five weeks after the first group arrived and 2-7 $d$ after the second group arrived, the first group (now adults P56; $\mathrm{T} @ \mathrm{P})$ and the second group (prepubertal P28; NoT@P) males were GDX. Four weeks later, under isoflurane anesthesia, all of the T@P (P84) and NoT@P (P56) males received two testosterone-filled capsules and bilateral microinjections of recombinant adeno-associated viral ( $\mathrm{rAAV}$ ) vectors encoding either green fluorescence protein (GFP) or GFP and wild-type $\triangle$ FosB aimed at the IL. Thus, there were three groups: T@P-GFP, NoT@P-GFP, and NoT@P- $\Delta$ FosB. For the microinjections, a small hole was drilled in the skull and a 5- $\mu$ l Hamilton syringe (26-gauge, Hamilton) was lowered at a $20^{\circ}$ angle to the level of the IL (3.3 $\mathrm{mm}$ rostral, $\pm 1.6 \mathrm{~mm}$ lateral, and $4.5 \mathrm{~mm}$ ventral relative to bregma) based on the Morin and Wood (2001) atlas. The syringe was kept in place for $2 \mathrm{~min}$ before injections and then either rAAV- $\Delta$ FosB or rAAV-GFP (1.0 $\mu l$ per hemisphere) was injected into the IL over 10 min, with the syringe kept in place for an additional 5 min after injection was complete. AAV2/5 viral vectors were purchased from the University of North Carolina Viral Vector Core, and titres were $\sim 1.0 \times 10^{13}$ transducing particles per microliter. These AAV vectors reach maximal expression around $10 \mathrm{~d}$ and sustain expression indefinitely (Vialou et al., 2010; Eagle et al., 2015; Sarno and Robison, 2018). These vectors only infect neurons and are no more toxic than vehicle alone (Zachariou et al., 2006). This AAV overexpression methodology provides the advantages of temporal (in this case, adulthood) and spatial (in this case, IL neurons) specificity, and the disadvantages of a greater level of expression than is typically seen in neurons and expression throughout the neuron, rather than specifically in the nucleus (Vialou et al., 2010; Robison et al., 2013; Eagle et al., 2015). As no other strategy for testing the role of $\Delta$ FosB in hamsters is currently available, we feel the advantages of viral overexpression outweigh the disadvantages, and this approach can yield critical new understanding of the molecular mechanisms of hamster behavior. Two weeks later (P70 and P98, respectively), all of the males from each group underwent sexual behavior testing over the next five weeks, as described in General Methods above.

\section{Viral vector placement, exclusion criteria, and sample sizes}

Based on the previously described behavioral outlier criteria for experiment 1, one NoT@P- $\Delta$ FosB male was an extreme high outlier for ectopic mounts per minute after sexual experience. Additionally, males were excluded from behavioral analysis if injections were misplaced or the viral vector was not expressed $(n=8)$, or if they displayed impaired motor behavior (e.g., difficulty walking or slowed movement) following stereotaxic surgery ( $n=$ 2). The GFP control males were included in analyses if the overexpression was located within any subregion of the $\mathrm{mPfC}$, whereas NoT@P- $\Delta$ FosB males were included only if the overexpression was located bilaterally in the IL. Of the five NoT@P- $\Delta$ FosB males removed from analysis, three of them had evidence of viral vector expression in other regions of the brain (two in the $\mathrm{Cg} 1 /$ posterior PrL and one in the secondary motor cortex), while the other two males did not show any evidence of viral vector expression. Thus, a total of 10 males were excluded from behavioral analysis yielding a total of 24 males, with T@PGFP $n=7$, NoT@P-GFP $n=10$, and NoT@P- $\Delta$ FosB $n=$ 7. It should be noted that in four out of the seven NoT@P$\Delta$ FosB group, overexpression of $\Delta$ FosB occurred in both the IL and the ventral region of the PrL. Final sample sizes for each behavior analyzed are provided in the respective figures or figure legends.

\section{Sexual behavior statistical analysis}

Statistical analysis for sexual behavior in experiment 2 was the same as previously described for experiment 1. In addition, the nature of the main effect of experimental group (T@P-GFP, NoT@P-GFP, NoT@P- $\Delta$ FosB) was determined using a Bonferroni correction, and interactions were followed up by one-way ANOVAs for between subject measures or MLM for repeated measures within a subset of animals, as appropriate. $p \leq 0.05$ was considered significant.

\section{Tissue processing}

Twenty-four hours after the final behavior test, all hamsters were deeply anesthetized with an overdose of sodium pentobarbital (150 mg/kg, i.p.). Blood was collected via cardiac puncture, and the animals were perfused with $100 \mathrm{ml}$ of buffered saline rinse and $150 \mathrm{ml}$ of $4 \%$ paraformaldehyde. Brains were collected, postfixed overnight in $4 \%$ paraformaldehyde, and then stored in $20 \%$ sucrose until sectioning. To verify the correct placement of the injection using GFP as a marker, sections were cut into $40-\mu \mathrm{m}$ coronal sections using a cryostat and stored in cryoprotectant for 30-60 min until mounting. The sections were then washed in TBS, mounted, and coverslipped while still wet with Vectashield hard set mounting medium (Vector Laboratories). The $\Delta$ FosB vector contains a segment expressing GFP, allowing for the injection site and extent of infection of cells to be verified by GFP visualization using an Olympus BX51 microscope under fluorescence illumination.

\section{Radioimmunoassay}

Plasma from blood collection was used to determine testosterone concentrations by radioimmunoassay as described above for Experiment 1. The intra-assay coefficient of variance was $5.4 \%$ and the minimum limit of detectability was $0.11 \mathrm{ng} / \mathrm{ml}$. All males had adult physiologic concentrations of circulating testosterone, with no significant differences among the groups (T@P-GFP $4.07 \pm 1.16 \mathrm{ng} / \mathrm{ml}$, NoT@P-GFP $4.76 \pm 0.85 \mathrm{ng} / \mathrm{ml}$, NoT@P- $\Delta$ FosB $3.84 \pm 0.73 \mathrm{ng} / \mathrm{ml}$ ). 
Table 2. Statistics for sham controls

\begin{tabular}{|c|c|c|c|}
\hline Figure & Independent variable(s) & Dependent variable & Statistics (*significant) \\
\hline NA & Sexual experience & $\begin{array}{l}\text { Latency to mount } \\
\text { Latency to intromit } \\
\text { Latency to ejaculate } \\
\text { Intromissions to ejaculation } \\
\Delta \text { FosB in the IL }\end{array}$ & $\begin{array}{l}F_{(1,24)}=14.65 ; p=0.001 * \\
F_{(1,24)}=14.33 ; p=0.001 * \\
F_{(1,24)}=31.27 ; p=0.001 * \\
F_{(1,17)}=12.24 ; p=0.003 * \\
F_{(1,23)}=4.45 ; p=0.046 *\end{array}$ \\
\hline
\end{tabular}

\section{Experiment 3: determine the effects of sexual experience and overexpression of $\Delta F$ osB in IL on dendritic spine number and morphology}

Experiments 1 and 2 provided evidence that pubertal testosterone programs sexual proficiency through the regulation of $\Delta$ FosB in the IL. To explore a possible mechanism through which $\Delta$ FosB in the IL mediates this experience-induced plasticity, experiment 3 investigated whether sexual experience and overexpression of $\Delta$ FosB in IL have similar effects on IL dendritic spine number and morphology, as has been reported for sexual experience and $\triangle$ FosB in NAc (Pitchers et al., 2013).

\section{Animals}

A total of 10 gonad-intact adult male hamsters were used for this experiment. Stereotaxic surgery and sexual behavior testing were performed as described in experiment 2. Hamsters were randomly assigned to one of three groups to investigate the effects of sexual experience and $\Delta$ FosB overexpression on spine density in the IL: sexually naive plus GFP (naive-GFP; $n=4$ ), sexually experienced (experienced-GFP; $n=3$ ), and sexually naive plus $\Delta$ FosB (naive- $\Delta$ FosB; $n=3$ ) males. AAV injections were performed as previously described in experiment 2 . Twentyone days later, males in the experienced-GFP group underwent five weeks of sexual behavior experience as described above in General methods Sexual behavior testing; males in the naive-GFP and naive- $\Delta$ FosB groups were placed in clean empty glass aquaria for $5 \mathrm{~min}$ in lieu of a sexual behavior experience.

\section{Tissue collection and processing}

Twenty-four hours after the final behavior test, all hamsters were deeply anesthetized with an overdose of sodium pentobarbital (150 $\mathrm{mg} / \mathrm{kg}$, i.p.). Animals were then transcardially perfused with 100-ml ice-cold PBS followed by $150-\mathrm{ml} 4 \%$ paraformaldehyde. Brains were postfixed $24 \mathrm{~h}$ in 4\% paraformaldehyde and cryopreserved in $20 \%$ sucrose. Brains were cut into $100 \mu \mathrm{m}$ sections on a Vibratome 3000 EP (Leica Microsystems) and rinsed in PBS. Free-floating immunofluorescent staining was performed using a goat anti-GFP primary antibody (ab5450, 1:1000, Abcam) followed by an Alexa Fluor 488 secondary antibody (705-545-147, 1:200, Jackson ImmunoResearch). Sections were mounted on slides using DPX mounting medium (Sigma-Aldrich).

\section{Dendritic spine quantification}

GFP/Alexa Fluor 488 fluorescence was visualized using an Olympus FluoView 1000 Filter-based Laser Scanning Confocal Microscope with the z-step size of $0.5 \mu \mathrm{m}$ and numerical aperture of 1.40 using a $100 \times$ lens. Spines were on the dendritic arbors of cortical pyramidal neurons in IL Layers III, V, and VI, and analyzed essentially as previously described (Christoffel et al., 2011). Briefly, dendritic segments 50-150 $\mu \mathrm{m}$ away from the soma were randomly chosen from IL neurons that expressed GFP. Z-stack images were acquired for reconstruction and morphologic analysis using NeuronStudio with the rayburst algorithm. NeuronStudio classifies spines as thin, mushroom, or stubby based on the following values: (1) aspect ratio, (2) head to neck ratio, and (3) head diameter. Spines with a neck can be classified as either thin or mushroom, and those without a significant neck are classified as stubby. Spines with a neck are labeled as thin or mushroom based on head diameter.

\section{Dendritic spine statistical analysis}

The three groups were analyzed for differences in dendritic spine density by one-way ANOVA followed by Bonferroni post hoc test for pairwise differences between individual groups. In this model, the unit of analysis was the number of dendrites within each animal group, yielding sample sizes as: naive-GFP, 22; experienced-GFP, 21 ; and naive- $\Delta$ FosB, $22 ; p \leq 0.05$ was considered significant. Statistical analysis was performed using IBM SPSS software (version 19).

\section{Results}

Statistics for all results are reported in respective tables.

\section{Sham controls: age at surgery does not affect sexual behavior or $\Delta$ FosB in the $\mathrm{MPfC}$}

Sham controls were used to confirm that any differences we found between T@P and NoT@P males are due to hormonal manipulation and not age of testing or surgery. The sham-T@P and sham-NoT@P males were tested at the same time and using the same protocol as experiment 1 . There were no significant differences between the two sham groups for any of the behaviors (data not shown). In both groups, latency to mount, latency to intromit, latency to ejaculate, and intromissions to ejaculation all significantly decreased with sexual experience (Table 2). Additionally, the two sham groups did not differ in overall expression of $\Delta \mathrm{FosB}$ in the $\mathrm{mPfC}$ subregions analyzed, and sexual experience induced $\Delta$ FosB in the IL in both sham groups (Table 2). These findings from the sham groups indicate that differences in behavioral or neural measures observed between T@P and NoT@P males are due to the presence or absence of testosterone during puberty, and not to age at the time of surgery or at the time of behavior testing. Results from sham groups will not be further discussed nor represented in the figures. 
Table 3. Statistics for experiment 1

\begin{tabular}{|c|c|c|c|c|c|}
\hline Figure & Independent variable(s) & Dependent variable & Statistics (*significant) & $\begin{array}{l}\text { Post hoc comparison } \\
\text { (if appropriate) }\end{array}$ & $\begin{array}{l}\text { Post hoc statistics } \\
\text { (*significant) }\end{array}$ \\
\hline & $\begin{array}{l}\text { Pubertal testosterone } \times \\
\text { sexual experience }\end{array}$ & & $\begin{array}{l}F_{(1,27)}=0.54 \\
p>0.05\end{array}$ & & \\
\hline \multirow[t]{9}{*}{3} & Pubertal testosterone & Latency to mount & $\begin{array}{l}F_{(1,27)}=0.272 \\
p>0.05\end{array}$ & & \\
\hline & Sexual experience & & $\begin{array}{l}F_{(1,27)}=17.43 \\
\quad p<0.001 *\end{array}$ & & \\
\hline & $\begin{array}{l}\text { Pubertal testosterone } \times \\
\text { sexual experience }\end{array}$ & & $\begin{array}{l}F_{(1,27)}=0.309 \\
\quad p>0.05\end{array}$ & & \\
\hline & Pubertal testosterone & Latency to intromit & $\begin{array}{l}F_{(1,27)}=1.01 \\
p>0.05\end{array}$ & & \\
\hline & Sexual experience & & $\begin{array}{l}F_{(1,27)}=15.84 \\
p<0.001 *\end{array}$ & & \\
\hline & & & & $\begin{array}{l}\text { Pubertal testosterone in } \\
\text { experienced males }\end{array}$ & $\begin{array}{l}F_{(1,27)}=0.641 \\
p>0.05\end{array}$ \\
\hline & Pubertal testosterone & $\begin{array}{l}\text { Intromissions to } \\
\text { ejaculation }\end{array}$ & $\begin{array}{l}F_{(1,26)}=0.465 \\
p>0.05\end{array}$ & & \\
\hline & Sexual experience & & $\begin{array}{l}F_{(1,26)}=25.00 \\
p<0.001 *\end{array}$ & & \\
\hline & $\begin{array}{l}\text { Pubertal testosterone } \times \\
\text { sexual experience }\end{array}$ & & $\begin{array}{l}F_{(1,26)}=2.73 \\
p>0.05\end{array}$ & & \\
\hline \multirow[t]{3}{*}{$4 D$} & $\begin{array}{l}\text { Pubertal testosterone } \times \\
\text { sexual experience }\end{array}$ & $\Delta$ FosB in the IL & $\begin{array}{c}F_{(1,23)}=10.86 \\
p=0.003 *\end{array}$ & $\begin{array}{l}\text { sexual experience in } \\
\text { T@P males } \\
\text { sexual experience in } \\
\text { NoT@P males }\end{array}$ & $\begin{array}{c}\boldsymbol{F}_{(\mathbf{1 , 1 2})}=\mathbf{1 4 . 0 6} \\
\boldsymbol{p}=\mathbf{0 . 0 0 3} \\
F_{(1,11)}=0.721 \\
p>0.05\end{array}$ \\
\hline & Sexual experience & & $\begin{array}{l}F_{(1,23)}=2.04 \\
p>0.05\end{array}$ & & \\
\hline & $\begin{array}{l}\text { Pubertal testosterone } \times \\
\text { sexual experience }\end{array}$ & & $\begin{array}{l}F_{(1,23)}=2.57 \\
\quad p>0.05\end{array}$ & & \\
\hline \multirow[t]{5}{*}{$5 C$} & $\begin{array}{l}\text { Pubertal testosterone } \times \\
\text { sexual experience }\end{array}$ & $\begin{array}{l}\Delta \text { FosB in the NAc } \\
\text { core }\end{array}$ & $\begin{array}{c}F_{(1,23)}=5.42 \\
p=0.029 *\end{array}$ & $\begin{array}{l}\text { Sexual experience in } \\
\text { T@P males }\end{array}$ & $\begin{array}{c}F_{(1,12)}=9.66 \\
p=0.009 *\end{array}$ \\
\hline & & & & $\begin{array}{l}\text { Sexual experience in } \\
\text { NoT@P males }\end{array}$ & $\begin{array}{l}F_{(1,11)}=0.042 \\
p>0.05\end{array}$ \\
\hline & Pubertal testosterone & $\begin{array}{l}\Delta \text { FosB in the NAc } \\
\text { shell }\end{array}$ & $\begin{array}{l}F_{(1,23)}=1.60 \\
p>0.05\end{array}$ & & \\
\hline & Sexual experience & & $\begin{array}{c}F_{(1,23)}=7.041 \\
p=0.014 *\end{array}$ & & \\
\hline & $\begin{array}{l}\text { Pubertal testosterone } \times \\
\text { sexual experience }\end{array}$ & & $\begin{array}{l}F_{(1,23)}=2.68 \\
\quad p>0.05\end{array}$ & & \\
\hline
\end{tabular}

\section{Experiment 1: pubertal testosterone programs behavioral adaptations to sexual experience and experience-dependent expression of $\Delta F$ osB in the mPfC and NAc (Table 3)}

The absence of testosterone during puberty led to significantly higher overall rates of ectopic mounting in NoT@P males compared with T@P males, independent of sexual experience (Fig. 2). Although the pubertal testosterone $\times$ sexual experience interaction was not statistically significant, only T@P males showed a clear decrease in the rate of ectopic mounting with sexual experience (naive mean \pm SEM rate: $0.492 \pm 0.156$, experienced mean \pm SEM rate: $0.239 \pm 0.156)$ compared to NoT@P males (naive mean \pm SEM rate: $0.748 \pm 0.151$, experi- 


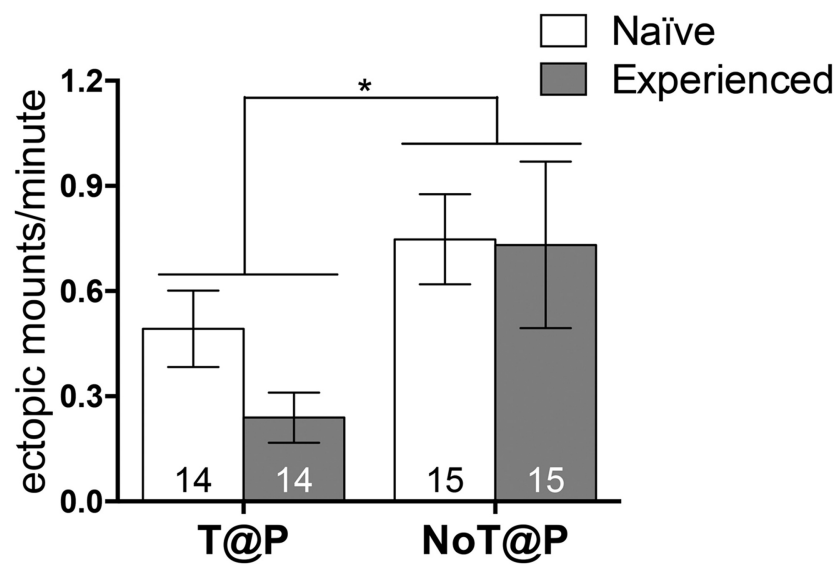

Figure 2. Rate of ectopic mounting is dependent on pubertal testosterone. T@P males had significantly fewer ectopic mounts per minute compared to NoT@P males. Bars represent mean $( \pm$ SEM); numbers on bars indicate sample size. $*$ Main effect of pubertal testosterone, $p \leq 0.05$.

enced mean \pm SEM rate: $0.732 \pm 0.151)$. In contrast, the latency to mount, latency to intromit, and number of intromissions to reach ejaculation were all significantly reduced by sexual experience (Fig. 3), independent of pubertal testosterone. There was an interaction between sexual experience and pubertal testosterone for ejaculation latency because latency to ejaculate was much higher in naive NoT@P males compared with naive T@P males (Fig. 3).

The subregions of the $\mathrm{mPfC}$ were traced according to the Morin and Wood (2001) hamster atlas (Fig. 4A) as shown by a representative microphotograph in Figure $4 B$. Sexual experience led to a significant increase in $\triangle F o s B$ expression in the IL of the mPfC only in T@P males (Fig. $4 C, D)$. In contrast, sexual experience did not increase $\Delta$ FosB expression in the $\mathrm{Cg} 1$ or $\mathrm{PrL}$ in either T@P or NoT@P males (Fig. 4D). Although the interaction between pubertal testosterone and experience was not statistically significant within the PrL $(p=0.122)$, experience appeared to increase $\Delta$ FosB expression in the PrL in T@P, but not NoT@P, males.

The shell and core of the NAc were also traced according to the Morin and Wood (2001) hamster atlas (Fig. $5 A$ ) with a representative microphotograph shown in Figure $5 B$. Sexual experience significantly increased $\Delta$ FosB expression in the NAc core only in T@P males (Fig. 5C). Sexual experience led to a significant increase in $\triangle$ FosB expression in NAc shell (Fig. 5C); however, pubertal testosterone did not affect $\Delta$ FosB expression
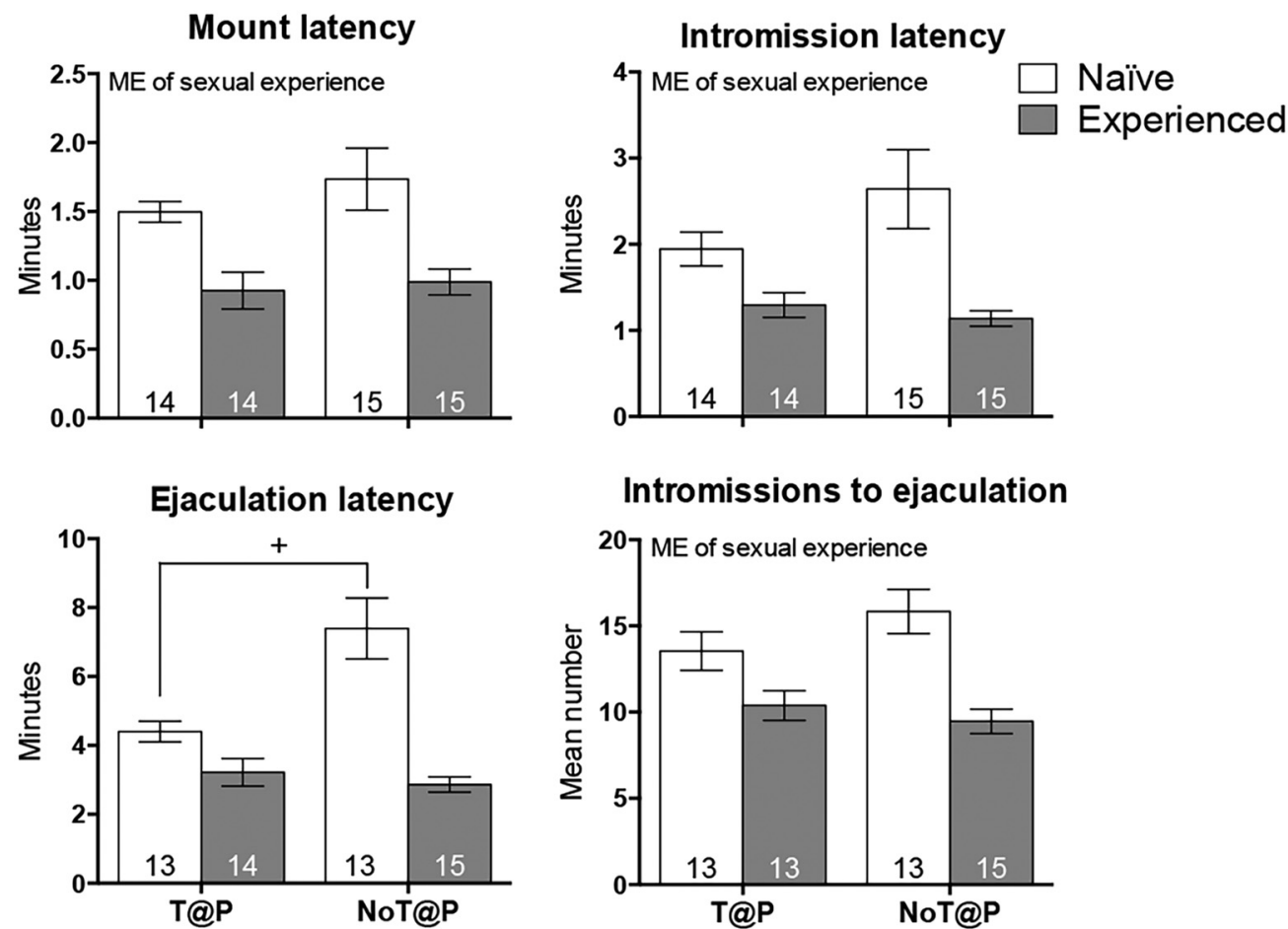

Intromissions to ejaculation

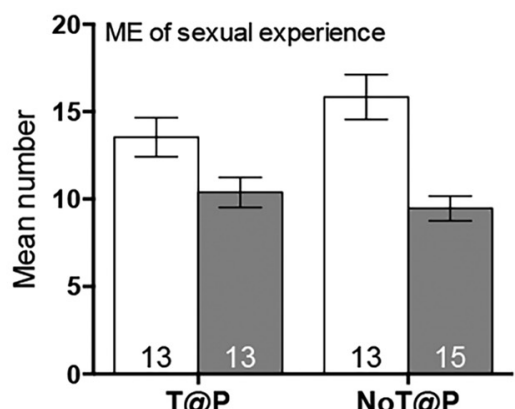

Figure 3. The effects of pubertal testosterone and sexual experience on latency to mount, intromit, and ejaculate and number of intromissions to ejaculation. Mount latency: there was a main effect (ME) of sexual experience on mount latency with sexually experienced males having shorter latencies to mount compared to sexually naive males. Intromission latency: There was an ME of sexual experience on intromission latency with sexually experienced males having shorter latencies to intromit compared to sexually naive males. Ejaculation latency: there was a pubertal testosterone $\times$ sexual experience interaction on ejaculation latency with sexually naive NoT@P males having a longer latency to ejaculate compared to sexually naive T@P males. This effect was not seen in sexually experienced males. Intromissions to ejaculate: there was an ME of sexual experience for intromissions to ejaculate with sexually experienced males having less intromissions to achieve ejaculation compared to sexually naive males. Bars represent mean ( \pm SEM); numbers on bars indicate sample size. + Interaction between pubertal testosterone and sexual experience, $p \leq 0.05$. 
A

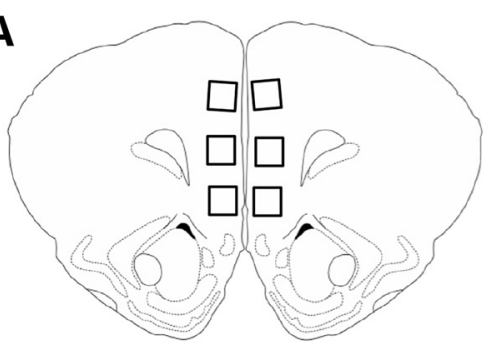

B

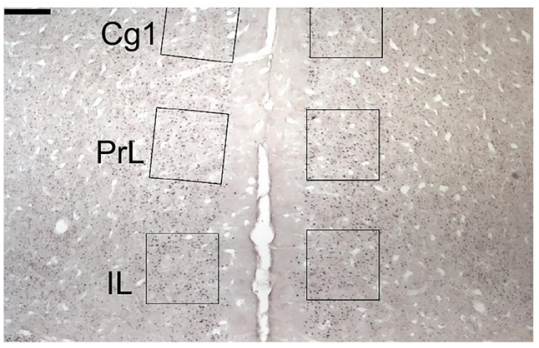

C

naïve

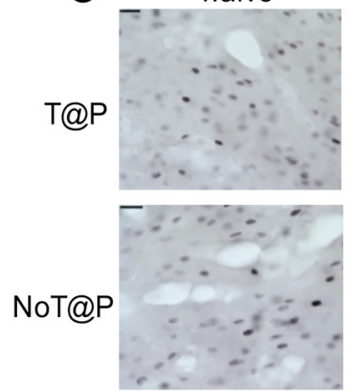

experienced

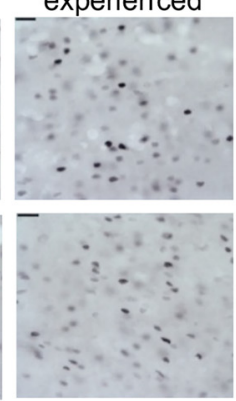

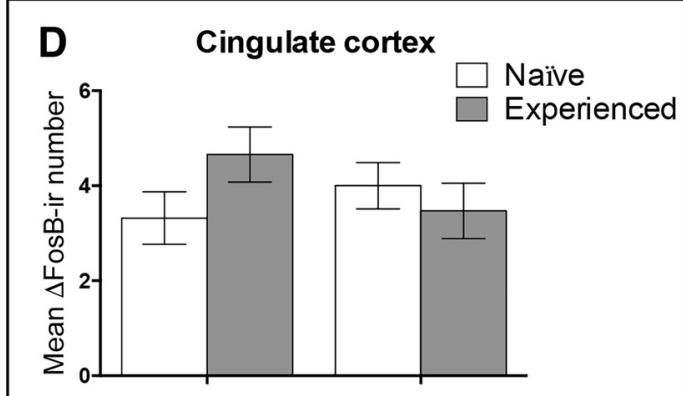

Prelimbic cortex

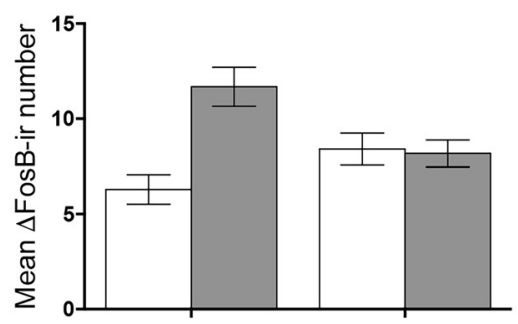

Infralimbic cortex

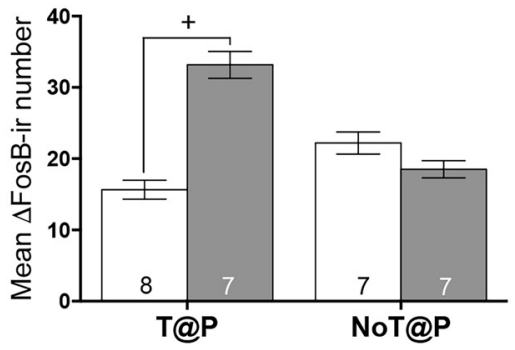

Figure 4. Number of $\Delta$ FosB-ir cells in IL is dependent on pubertal testosterone and sexual experience. $\boldsymbol{A}$, Brain atlas (Morin and Wood, 2001) representation of a coronal section containing the $\mathrm{mPfC}$. $\boldsymbol{B}$, Photomicrographs of drawn contours of the mPfC onto immunohistochemically-treated tissue sections at $4 \times$ objective. The $\mathrm{mPfC}$ included the anterior $\mathrm{Cg} 1$, PrL, and IL cortices; scale bar $=250 \mu \mathrm{m}$. C . The $2 \times 2$ panel of photomicrographs below the bar graph are representative images of $\Delta$ FosB-ir in the IL for the specified group of males; scale bars $=25 \mu \mathrm{m}$. $\boldsymbol{D}$, In the $\mathrm{CgL}$ and $\mathrm{PrL}$, there were no effects or interactions of pubertal testosterone and sexual experience on $\Delta$ FosB-ir cells, respectively. In the IL, there was an interaction between pubertal testosterone and sexual experience on $\Delta$ FosB-ir cells with sexual experienced T@P males having significantly more $\Delta$ FosB-ir cells compared to sexually naive T@P males. There were no significant differences in $\Delta$ FosB-ir cells as a function of sexual experience within NoT@P males. Bars represent mean ( \pm SEM); numbers on bars indicate sample size. + Interaction between pubertal testosterone and sexual experience, $p \leq 0.05$.

in the shell nor was there an interaction. Similar to the PrL, although the interaction between pubertal testosterone and experience was not statistically significant within the shell $(p=0.115)$, experience appeared to increase $\Delta$ FosB expression in the shell in T@P, but not NoT@P, males.

\section{Experiment 2: overexpression of $\Delta$ FosB in the IL restores social proficiency in NoT@P males (Table 4)}

Placement of the injection site and extent of transduced cells in the IL was verified using fluorescence microscopy (Fig. 6). Overexpression of $\Delta$ FosB in the IL decreased the overall rate of ectopic mounting (Fig. 7), with NoT@P- $\Delta$ FosB males displaying less ectopic mounts per minute than NoT@P-GFP males. Sexual experience did not affect the rate of ectopic mounting, nor was there an interaction between experimental group and sexual experience. Interestingly, sexually naive NoT@P- $\Delta$ FosB males had similar rates of ectopic mounting as sexually experienced T@P males, suggesting that they become sexually proficient within a single sexual encounter.

Sexual experience significantly reduced the latency to intromit, latency to ejaculate, and number of intromissions to reach ejaculation (Fig. 8), independent of overexpression of $\Delta$ FosB in the IL, and with no interactions. There was an interaction between sexual experience and overexpression of $\triangle \mathrm{FosB}$ in the IL for mount latency due to sexual experience decreasing the latency to mount in NoT@P- $\Delta$ FosB males, but not in GFP control males (Fig. 8). To assess region specificity, behaviors of the three NoT@P- $\Delta$ FosB males with misplaced injections were compared with those of NoT@P- 
A

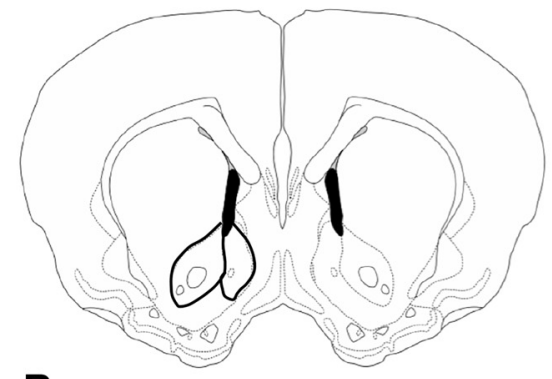

B

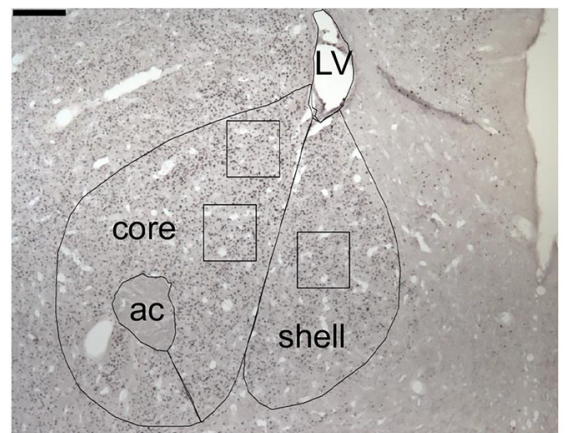

C

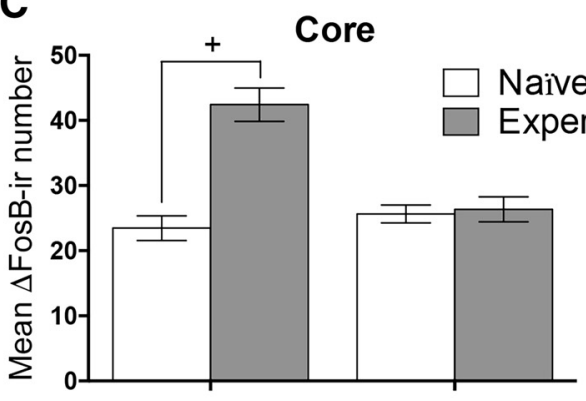

Shell

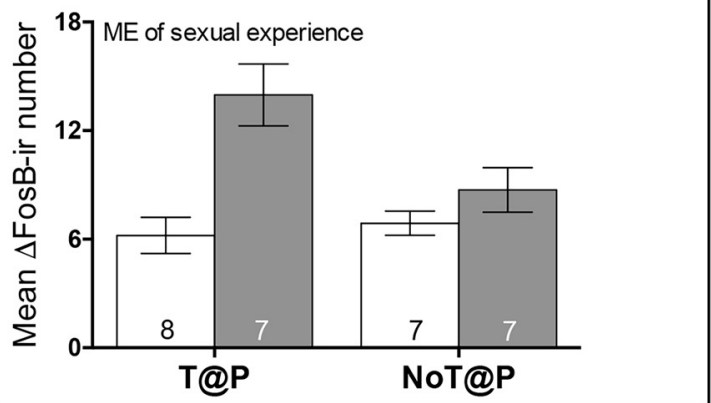

Figure 5. Number of $\Delta$ FosB-ir cells in the NAc core and shell is dependent on pubertal testosterone and sexual experience. $\boldsymbol{A}$, Brain atlas (Morin and Wood, 2001) representation of a coronal section containing the NAc. B, Photomicrographs of drawn contours of the NAc onto immunohistochemically-treated tissue sections. The NAc included the shell and core. LV = lateral ventricle; ac $=$ anterior commissure. Scale bar $=250 \mu \mathrm{m}$. $\boldsymbol{C}$, In the core, there was an interaction between pubertal testosterone and sexual experience on $\Delta$ FosB-ir cells with sexual experienced T@P males having significantly more $\Delta$ FosB-ir cells compared to sexually naive T@P males. There were no significant differences in $\Delta$ FosB-ir cells as a function of sexual experience within NoT@P males. In the shell, there was a main effect (ME) of sexual experience on $\Delta$ FosB-ir cells with sexually experienced males having more $\Delta$ FosB-ir expression compared to sexually naive males. Bars represent mean ( \pm SEM); numbers on bars indicate sample sizes. + Interaction between pubertal testosterone and sexual experience, $p \leq 0.05$.

$\Delta$ FosB males with accurately placed injections. Due to the low sample size and variable brain region hits, these data were not analyzed statistically, but overall NoT@P$\Delta$ FosB males with misplaced injections did not show evidence of social proficiency similar to that seen in NoT@P- $\Delta$ FosB males with accurately placed injections (data not shown).

\section{Experiment 3: both sexual experience and overexpression of $\Delta F$ FosB increase spine density in the IL (Table 5)}

Overexpression of $\Delta F o s B$ in the IL increased thin dendritic spine density (Fig. 9B), with naive- $\Delta$ FosB males having significantly more thin spines compared to both groups of GFP males. There was no effect of sexual experience or overexpression of $\triangle \mathrm{FosB}$ in the $\mathrm{IL}$ on stubby spines (Fig. 9B). Sexual experience significantly increased mushroom spine density (Fig. 9B), with experienced-GFP males having more mushroom spines compared to naive-GFP males. Overexpression of $\Delta$ FosB in the IL increased total dendritic spine density (Fig. 9B), with naive- $\Delta$ FosB males having significantly more total spines compared to naive-GFP control males and experienced-GFP males not differing significantly from either group. Thus, we found that males with overexpressed $\triangle F$ osB in the IL had a significant increase in total spine density driven by a significant increase in thin spines and a (nonsignificant) increase in mushroom spines.

\section{Discussion}

These studies provide evidence that during puberty, testosterone is necessary for experience-dependent induction of $\Delta$ FosB in the IL, thereby programming sexual proficiency in adulthood, possibly through modulation of synaptic lability. We first replicated our previous finding that pubertal testosterone is required for male hamsters to display behavioral adaptations with sexual experience (i.e., social proficiency). We then showed that the presence of testosterone during puberty is necessary for social experience-dependent increases in $\triangle F$ osB in both the ventral $\mathrm{MPFC}$ and NAc core, providing a correlation between dysregulation of $\triangle \mathrm{FosB}$ and impairment in social proficiency. Next, we demonstrated that overexpression of $\Delta$ FosB in the IL is sufficient to restore a socially proficient phenotype in males that lacked testosterone during puberty. In addition, both $\triangle F o s B$ and sexual experience increase the density of dendritic spines on IL neurons, albeit in different patterns, suggesting a potential mechanism by which pubertal testosterone programs experience-dependent neural and behavioral adaptations in adulthood. To our knowledge, this is the first report to 
Table 4. Statistics for experiment 2

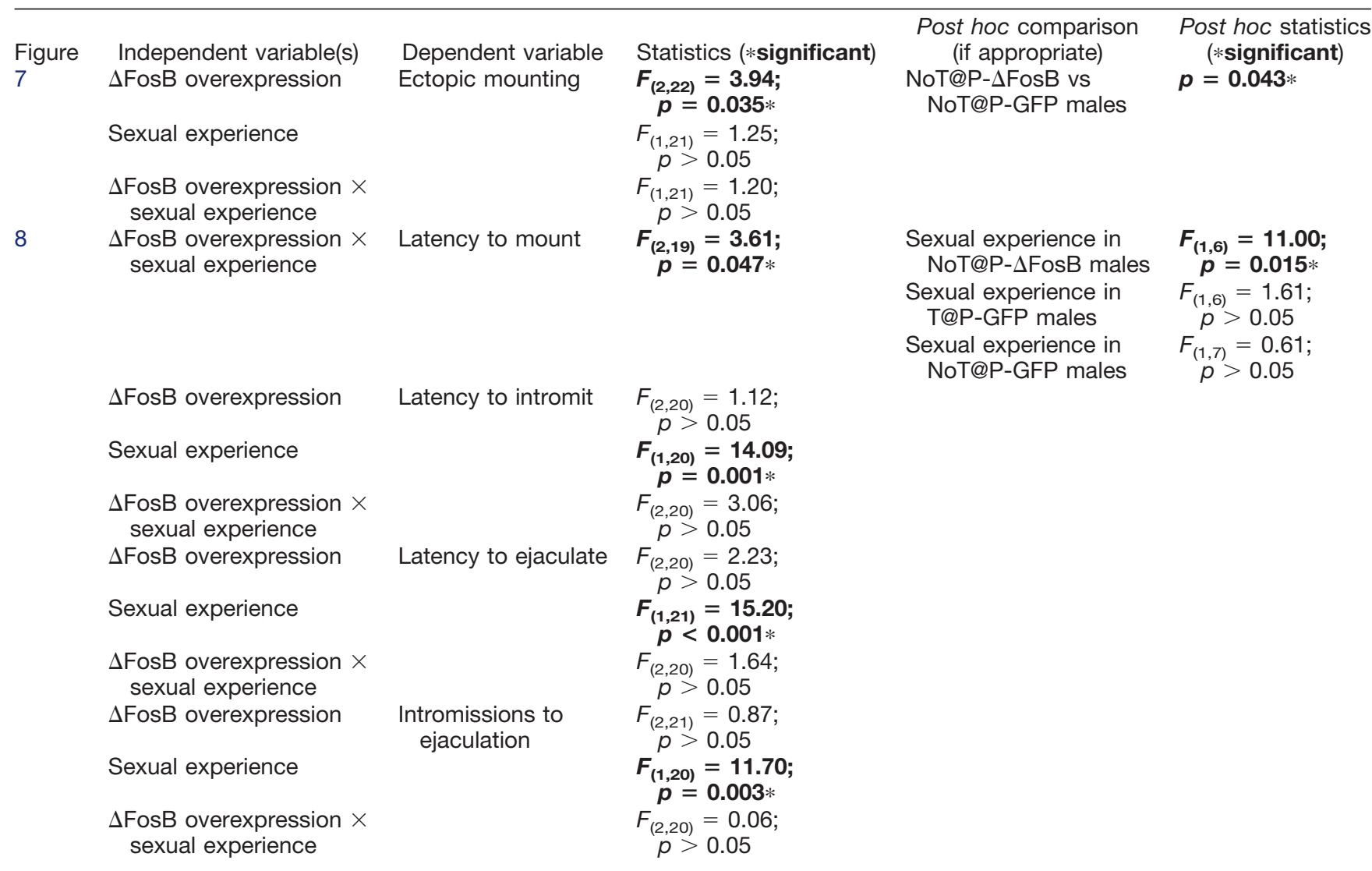

implicate $\Delta$ FosB as a key player in experience-dependent neural and behavioral plasticity that is hormonally programmed during a sensitive period of social development, providing new mechanistic insight into the development of social cognition during puberty and adolescence.

In the present study, we found that induction of $\Delta F$ osB in the IL occurred after sexual experience in only T@P males, suggesting a possible site of action in which pubertal testosterone programs the ability to inhibit maladaptive behaviors. Because $\Delta \mathrm{FosB}$ is induced by persistent neuronal activity (Robison and Nestler, 2011), these data may indicate that the IL is preferentially activated by sexual experience in $\mathrm{T} @ \mathrm{P}$ males, and is not activated to the same extent in NoT@P males. This suggests that pubertal testosterone may rewire the brain to allow increased excitatory input (or less inhibitory input) to the IL, which then regulates behavioral inhibition during social behaviors. Substantial projections from the ventral hippocampal formation (CA1 and subiculum, specifically) and the basolateral amygdala to the IL may contribute to the formation of social memories and social learning through reward-related experience, both of which are required for adaptive behavioral flexibility (Hoover and Vertes, 2007; Wassum and Izquierdo, 2015; Hegde et al., 2016). Indeed, ovarian hormones during puberty organize inhibitory transmission in the $\mathrm{Cg} 1$ region of the $\mathrm{mPfC}$ to
A

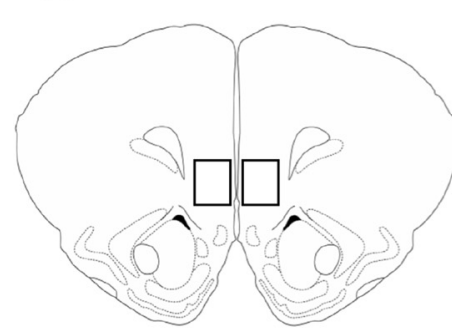

B

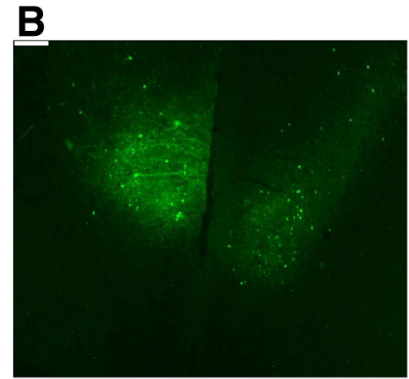

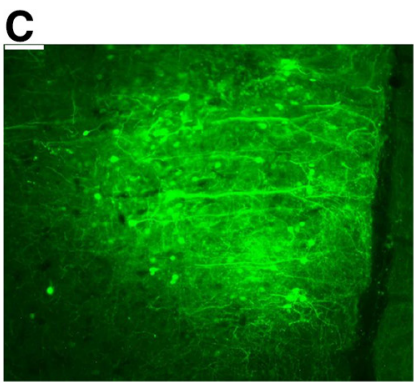

Figure 6. Visualization of GFP to verify injection site and extent of infected cells in the IL. $\boldsymbol{A}$, Boxes of representative injection sites in the IL for NoT@P- $\Delta$ FosB males over coronal atlas diagram (Morin and Wood, 2001). B, Photomicrograph of GFP overexpression in a NoT@P- $\Delta$ FosB male; scale bar $=250 \mu \mathrm{m}$. C, Photomicrograph of GFP overexpression in a NoT@P- $\Delta$ FosB male; scale bar $=100$ $\mu \mathrm{m}$. 


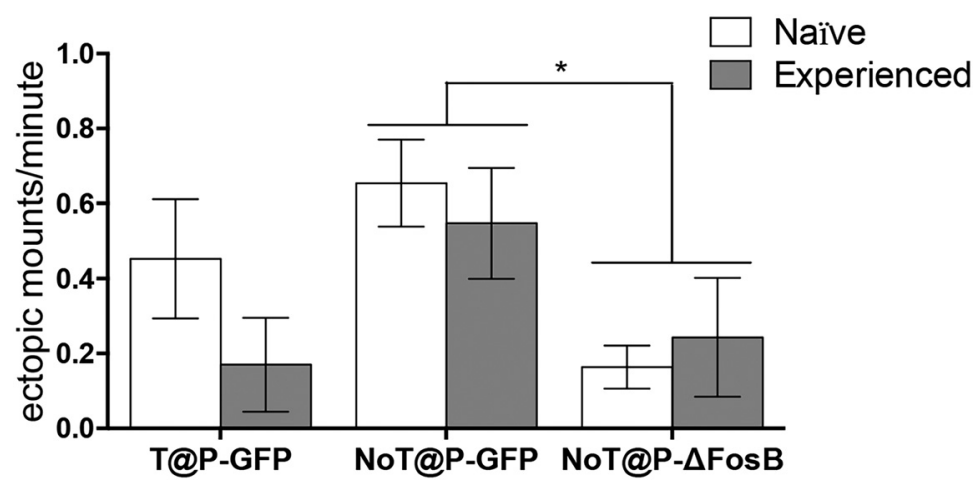

Figure 7. Overexpression of $\Delta$ FosB in the IL decreases the rate of ectopic mounting in NoT@P males. NoT@P- $\Delta$ FosB males $(n=6)$ had significantly less ectopic mounts per minute compared to NoT@P-GFP males $(n=9)$. T@P-GFP males $(n=7)$ did not differ from either group in rate of ectopic mounting. Bars represent mean $( \pm \mathrm{SEM})$. $*$ Main effect of experimental group, $p \leq 0.05$.

program behavioral flexibility in non-social learning tasks in mice (Piekarski et al., 2017). Thus, the notion that pubertal hormones rewire the brain to fine-tune behavioral inhibition is not unique to testicular hormones and social proficiency, and generalizes to ovarian hormones and other prefrontal-dependent forms of behavioral flexibility across species.

The ventral $\mathrm{mPfC}$, which includes the IL and PrL, is critical for behavioral inhibition in sexual contexts. Male rats with ventral $\mathrm{mPfC}$ lesions continue to mate with females even when sexual behavior is paired with aversive consequences (Davis et al., 2010). Furthermore, $\Delta$ FosB is integral in inducing neural plasticity in response to both natural and drug rewards by regulating gene expression (Nestler et al., 1999; McClung et al., 2004; Pitchers et al., 2013). Therefore, NoT@P males may not have the capacity for behavioral inhibition as a result of lacking this crucial $\Delta$ FosB-driven plasticity within the IL. Indeed, we found that NoT@P males overexpressing $\Delta$ FosB show low rates of ectopic mounting overall compared to control NoT@P males. Although NoT@P- $\Delta$ FosB males did not show a decrease in ectopic mounting with sexual experience, this is likely due to floor effect as they had very low rates even when sexually naive. In fact, sexually naive NoT@P- $\Delta$ FosB males had ectopic mounting rates similar to sexually experienced $\mathrm{T} @ \mathrm{P}$ males, suggesting that
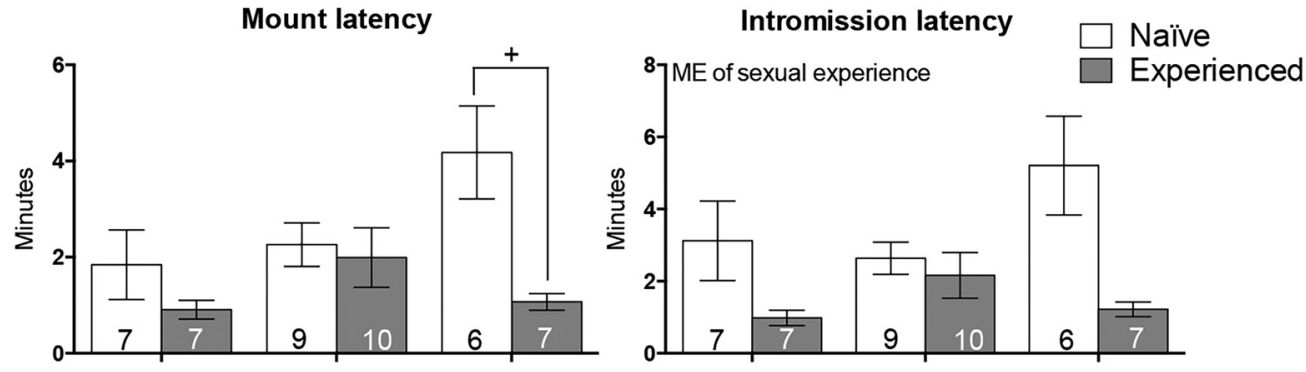

Ejaculation latency

Intromissions to ejaculation
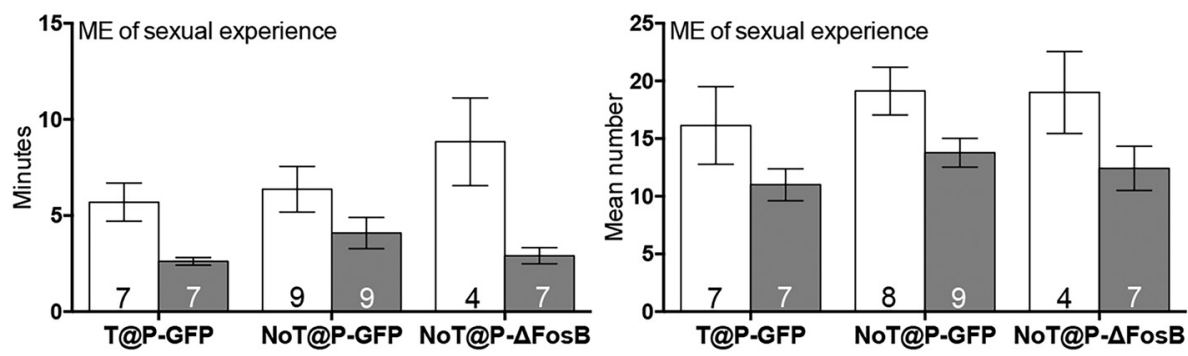

Figure 8. The effects of $\triangle$ FosB overexpression in the IL and sexual experience on latency to mount, intromit, and ejaculate and number of intromissions to ejaculation. For mount latency, there was a pubertal testosterone $\times$ sexual experience interaction with sexually naive NoT@P- $\Delta$ FosB males having a longer latency to mount compared to sexually experienced NoT@P- $\Delta$ FosB males. This effect of sexual experience was not found in T@P-GFP or NoT@P-GFP males. For intromission latency and ejaculation latency, there was a main effect of sexual experience with sexually experienced males having shorter latencies to mount and intromit compared to sexually naive males. For intromissions to ejaculate, there was a main effect (ME) of sexual experience with sexually experienced males having less intromissions to achieve ejaculation compared to sexually naive males. Bars represent mean ( \pm SEM); numbers on bars indicate sample size. + Interaction between experimental group and sexual experience, $p \leq 0.05$. 
Table 5. Statistics for experiment 3

\begin{tabular}{|c|c|c|c|c|c|}
\hline Figure & Independent variable(s) & Dependent variable & Statistics (*significant) & $\begin{array}{l}\text { Post hoc comparison } \\
\text { (if appropriate) }\end{array}$ & $\begin{array}{l}\text { Post hoc statistics } \\
\text { (*significant) }\end{array}$ \\
\hline \multirow[t]{5}{*}{$9 B$} & $\begin{array}{l}\text { Experimental group } \\
\text { (naive-GFP, } \\
\text { experienced-GFP, } \\
\text { naive- } \Delta \text { FosB ) }\end{array}$ & Thin spines & $\begin{array}{l}F_{(2,62)}=1.717 \\
\quad p<0.001 *\end{array}$ & $\begin{array}{l}\text { Naive- } \Delta \text { FosB vs } \\
\text { naive-GFP males }\end{array}$ & $p<0.001 *$ \\
\hline & & & & $\begin{array}{l}\text { Naive- } \Delta \text { FosB vs } \\
\text { experienced-GFP } \\
\text { males }\end{array}$ & $p=0.016 *$ \\
\hline & $\begin{array}{l}\text { Experimental group (naive-GFP, } \\
\text { experienced-GFP, } \\
\text { naive- } \Delta \text { FosB ) }\end{array}$ & Stubby spines & $\begin{array}{l}F_{(2,62)}=0.723 \\
\quad p>0.05\end{array}$ & & \\
\hline & $\begin{array}{l}\text { Experimental group } \\
\text { (naive-GFP, } \\
\text { experienced-GFP, } \\
\text { naive- } \Delta \text { FosB ) }\end{array}$ & Mushroom spines & $\begin{array}{l}F_{(2,61)}=4.080 \\
p=0.022 *\end{array}$ & $\begin{array}{l}\text { Naive-GFP vs } \\
\text { experienced-GFP } \\
\text { males }\end{array}$ & $p=0.029 *$ \\
\hline & $\begin{array}{l}\text { Experimental group } \\
\text { (naive-GFP, } \\
\text { experienced-GFP, } \\
\text { naive- } \Delta \text { FosB ) }\end{array}$ & Total spines & $\begin{array}{l}F_{(2,62)}=9.359 \\
\quad p<0.001 *\end{array}$ & $\begin{array}{l}\text { Naive- } \Delta \text { FosB vs } \\
\text { naive-GFP } \\
\text { males }\end{array}$ & $p<0.001 *$ \\
\hline
\end{tabular}

$\Delta$ FosB overexpression reduces this maladaptive behavior even in the absence of experience.

Our group and others have found that overexpression of $\Delta$ FosB causes an increase in immature dendritic spine number in medium spiny neurons of the NAc (Maze et al., 2010; Grueter et al., 2013; Robison et al., 2013) as well as in hippocampal pyramidal neurons (Eagle et al., 2015). Therefore, we hypothesized that $\Delta$ FosB might exert its effects on social proficiency through alterations in the number and structure of dendritic spines on IL pyramidal neurons. Indeed, we found that both sexual experience and overexpression of $\Delta$ FosB significantly increased the density of spines on IL pyramidal neurons, with sexual experience increasing mature mushroom spines and overexpression of $\Delta$ FosB increasing thin and total spines. These results are consistent with previous work: sexual experience in female hamsters increases NAc spine density (Staffend et al., 2014); in other rodents, sexual experience in males increases $\mathrm{mPfC}$ pyramidal neuron spine density (Glasper et al., 2015), early-life stress reduces both social interaction and mPfC spines (Farrell et al., 2016), and antidepressant treatment increases both dendritic spine number and $\Delta$ FosB expression in PfC (Li et al., 2010; Vialou et al., 2014). One intriguing potential explanation for these findings is that sexual experience increases $\triangle$ FosB expression driving an initial increase in thin spines, while consolidation of memories encoding learned sexual behavior is accompanied by a return to basal $\triangle F$ osB levels and a maturation of spines into a mushroom shape. In experiments in which $\Delta$ FosB expression is maintained virally without sexual experience, as we have done here, new immature spines are constantly generated, but no learning occurs to cause them to form into mature mushroom spines. The gene targets of $\Delta \mathrm{FosB}$ in the $\mathrm{mPfC}$ are largely unknown, though in other brain regions, including NAc, it regulates the expression of multiple genes critical for spine dynamics and glutamatergic synapse function, including $\mathrm{CaMKII} \alpha$ (Robison et al., 2013) and GluA2 (Kelz et al., 1999; Vialou et al., 2010). These studies, together with the current findings, suggest that $\Delta$ FosB increases the potential for synaptic plasticity via the formation of immature spines, and that behavioral experience is needed to promote conversion of labile thin spines into more stable mushroom spines.

Sexual proficiency is gained through learning from experience and making behavioral adaptations in part through the inhibition of behaviors that become maladaptive with experience, such as ectopic mounting. The major behavioral difference found between T@P and NoT@P males was rate of ectopic mounting. NoT@P males showed initial high rates of ectopic mounting and, even after sexual experience, continued to show high rates. Conversely, sexually naive T@P males had lower rates of ectopic mounting compared to NoT@P males, and also showed a decrease in ectopic mounting with sexual experience. Being able to inhibit behaviors that are maladaptive is imperative to successful social interactions. Therefore, these data indicate that pubertal testosterone programs the ability to inhibit behaviors that are not rewarding or advantageous, and thus, maladaptive.

Here, we provide evidence that pubertal testosterone organizes the ability to inhibit inappropriate behavior. However, there are some limitations to the present set of experiments. Although the male Syrian hamster is an excellent model to study both sexual reward and sexual proficiency, hamsters are a solitary species. Thus, the generalizability of our results to more social species is limited. Perhaps pubertal testosterone plays a bigger role in organizing the brain in solitary species compared to social species, as solitary animals do not have as much exposure to social experience to help shape the brain. Experiments that address this issue in a more social species, such as rats, would be useful. Additionally, sexual proficiency is only one example of social cognition, and it remains to be seen whether the principles we have derived from our studies on sexual proficiency generalize to other types of social proficiency and cognition. We have shown similar deficits in social cognition during male-male agonistic encounters of NoT@P males (Schulz et al., 2006; De Lorme and Sisk, 2013). Thus, we hypoth- 

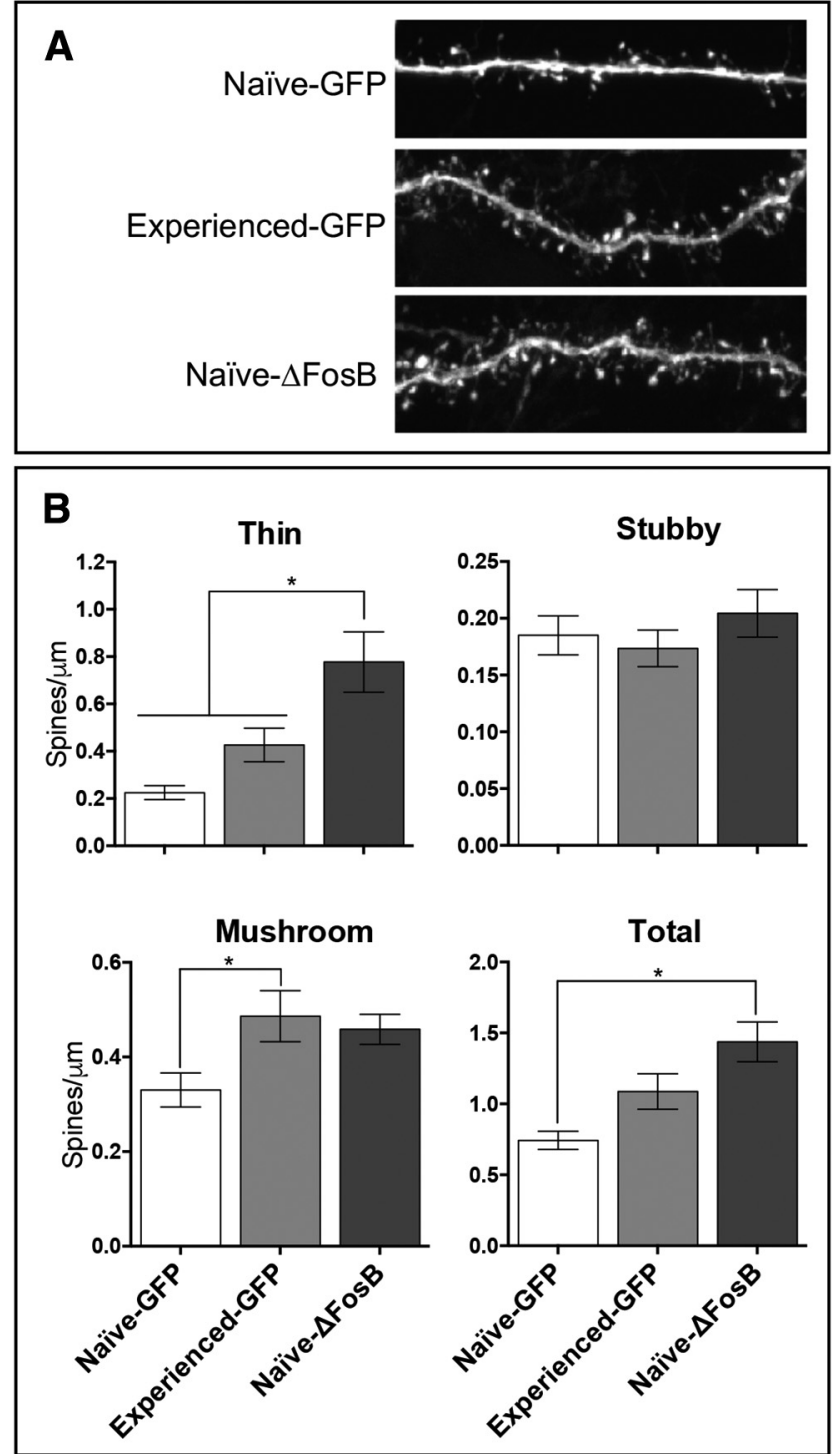

Figure 9. Both sexual experience and $\Delta$ FosB increase dendritic spines in vmPFC. $\boldsymbol{A}, \mathrm{AAV}-\mathrm{GFP}$ was injected into the IL of naive ( $n$ $=22)$ or sexually experienced $(n=21)$ males, and AAV-GFP$\Delta$ FosB was injected into the IL of naive males $(n=22)$. Immunofluorescence using a GFP antibody reveals spines of IL pyramidal neurons in all three groups. $\boldsymbol{B}$, Thin spine density was increased by $\Delta$ FosB overexpression. Stubby spine density was not affected by either sexual experience nor $\Delta$ FosB overexpression. Mushroom spine density increased with sexual experience and showed a trend to increase by $\Delta$ FosB overexpression. Overall, total spine density was increased by $\Delta$ FosB overexpression. Bars represent mean $( \pm$ SEM). * Main effect of experimental group, $p<0.05$.

esize that the social ineptness of NoT@P males is not unique to a specific social context, but reflects a more global dysfunction in the expression of contextappropriate social behavior. Finally, it is worth noting that we also found an increase in $\triangle F o s B$ in the NAc core after sexual experience in T@P, but not NoT@P, males, and it is possible that a similar increase in $\triangle \mathrm{FosB}$ and/or dendritic spine density occurred in other regions that we did not investigate. Therefore, although we have shown that over- expression of $\triangle F$ osB in ventral mPFC is sufficient to induce a socially proficient behavioral phenotype, additional experiments are needed to show that an increase in $\Delta \mathrm{FosB}$ in the IL is necessary for social proficiency to be acquired.

Given that social contexts are ever changing, social proficiency is a fundamental asset in adulthood because it increases the probability of successful social interactions. We show here that, in males, exposure to testosterone during puberty is critical for the ability to make behavioral adjustments with sexual experience. Without pubertal testosterone, males show neither the neural (increase in $\Delta$ FosB expression) nor behavioral (decrease in ectopic mounts) adaptations to sexual experience in adulthood that are observed in typically developing males. We also show that, in males who were exposed to testosterone during puberty, the overexpression of $\Delta \mathrm{FosB}$ in IL increases the density of immature spines and sexual experience increases the density of mature spines, suggesting a mechanism by which pubertal testosterone programs neural and behavioral plasticity in adulthood. We speculate that in the absence of testosterone during puberty, adult males fail to acquire social proficiency as a result of the lack of $\Delta$ FosB-induced formation of immature spines in the IL that could mature into functional glutamatergic synapses with social experience. That is, without the potential for neural plasticity in executive control brain regions, there is less potential for experience-dependent behavioral plasticity. The sites and mechanisms of action for hormonal programming of brain and behavior during puberty are largely unknown, and thus, our findings prompt new avenues of investigation to advance understanding of adolescent maturation of social cognition.

\section{References}

Christoffel DJ, Golden SA, Dumitriu D, Robison AJ, Janssen WG, Ahn HF, Krishnan V, Reyes CM, Han MH, Ables JL, Eisch AJ, Dietz DM, Ferguson D, Neve RL, Greengard P, Kim Y, Morrison JH, Russo SJ (2011) I $\left.\right|_{\kappa}$ kinase regulates social defeat stress-induced synaptic and behavioral plasticity. J Neurosci 31:314-321.

Davis JF, Loos M, Di Sebastiano AR, Brown JL, Lehman MN, Coolen LM (2010) Lesions of the medial prefrontal cortex cause maladaptive sexual behavior in male rats. Biol Psychiatry 67:1199-1204.

De Lorme KC, Sisk CL (2013) Pubertal testosterone programs context-appropriate agonistic behavior and associated neural activation patterns in male Syrian hamsters. Physiol Behav 112-113: $1-7$.

De Lorme KC, Sisk CL (2016) The organizational effects of pubertal testosterone on sexual proficiency in adult male Syrian hamsters. Physiol Behav 165:273-277.

De Lorme K, Bell MR, Sisk CL (2013) The teenage brain: social reorientation and the adolescent brain-the role of gonadal hormones in the male Syrian hamster. Curr Dir Psychol Sci 22:128133.

Eagle AL, Gajewski PA, Yang M, Kechner ME, Al Masraf BS, Kennedy PJ, Wang H, Mazei-Robison MS, Robison AJ (2015) Experience-dependent induction of hippocampal $\triangle$ FosB controls learning. J Neurosci 35:13773-13783.

Euston DR, Gruber AJ, McNaughton BL (2012) The role of medial prefrontal cortex in memory and decision making. Neuron 76: 1057-1070.

Farrell MR, Holland FH, Shansky RM, Brenhouse HC (2016) Sexspecific effects of early life stress on social interaction and pre- 
frontal cortex dendritic morphology in young rats. Behav Brain Res 310:119-125.

Glasper ER, LaMarca EA, Bocarsly ME, Fasolino M, Opendak M, Gould E (2015) Sexual experience enhances cognitive flexibility and dendritic spine density in the medial prefrontal cortex. Neurobiol Learn Mem 125:73-79.

Grueter BA, Robison AJ, Neve RL, Nestler EJ, Malenka RC (2013) FosB differentially modulates nucleus accumbens direct and indirect pathway function. Proc Natl Acad Sci USA 110:1923-1928.

Hegde S, Ji H, Oliver D, Patel NS, Poupore N, Shtutman M, Kelly MP (2016) PDE11A regulates social behaviors and is a key mechanism by which social experience sculpts the brain. Neuroscience 335 : 151-169.

Hedges VL, Chakravarty S, Nestler EJ, Meisel RL (2009) Delta FosB overexpression in the nucleus accumbens enhances sexual reward in female Syrian hamsters. Genes Brain Behav 8:442-449.

Hoover WB, Vertes RP (2007) Anatomical analysis of afferent projections to the medial prefrontal cortex in the rat. Brain Struct Funct 212:149-179.

Hull EM, Meisel RL, Sachs BD (2002) Male sexual behavior. San Diego, CA: Academic Press.

Kelz MB, Chen J, Carlezon WA Jr, Whisler K, Gilden L, Beckmann AM, Steffen C, Zhang YJ, Marotti L, Self DW, Tkatch T, Baranauskas G, Surmeier DJ, Neve RL, Duman RS, Picciotto MR, Nestler EJ (1999) Expression of the transcription factor deltaFosB in the brain controls sensitivity to cocaine. Nature 401:272-276.

Li J, Cheng Y, Bian W, Liu X, Zhang C, Ye JH (2010) Region-specific induction of FosB/ $\Delta$ FosB by voluntary alcohol intake: effects of naltrexone. Alcohol Clin Exp Res 34:1742-1750.

Maze I, Covington HE 3rd, Dietz DM, LaPlant Q, Renthal W, Russo SJ, Mechanic M, Mouzon E, Neve RL, Haggarty SJ, Ren Y, Sampath SC, Hurd YL, Greengard P, Tarakhovsky A, Schaefer A, Nestler EJ (2010) Essential role of the histone methyltransferase G9a in cocaine-induced plasticity. Science 327:213-216.

McClung CA, Ulery PG, Perrotti LI, Zachariou V, Berton O, Nestler EJ (2004) DeltaFosB: a molecular switch for long-term adaptation in the brain. Brain Res Mol Brain Res 132:146-154.

Morin LP, Wood RI (2001) A stereotaxic atlas of the Golden hamster brain. San Diego, CA: Academic Press.

Nelson EE, Leibenluft E, McClure EB, Pine DS (2005) The social re-orientation of adolescence: a neuroscience perspective on the process and its relation to psychopathology. Psychol Med 35:163174.

Nestler EJ, Kelz MB, Chen J (1999) DeltaFosB: a molecular mediator of long-term neural and behavioral plasticity. Brain Res 835:10-17.

Perrotti LI, Hadeishi Y, Ulery PG, Barrot M, Monteggia L, Duman RS, Nestler EJ (2004) Induction of deltaFosB in reward-related brain structures after chronic stress. J Neurosci 24:10594-10602.

Perrotti LI, Bolaños CA, Choi KH, Russo SJ, Edwards S, Ulery PG, Wallace DL, Self DW, Nestler EJ, Barrot M (2005) DeltaFosB accumulates in a GABAergic cell population in the posterior tail of the ventral tegmental area after psychostimulant treatment. Eur J Neurosci 21:2817-2824.

Perrotti LI, Weaver RR, Robison B, Renthal W, Maze I, Yazdani S, Elmore RG, Knapp DJ, Selley DE, Martin BR, Sim-Selley L, Bachtell RK, Self DW, Nestler EJ (2008) Distinct patterns of DeltaFosB induction in brain by drugs of abuse. Synapse 62:358-369.

Piekarski DJ, Boivin JR, Wilbrecht L (2017) Ovarian hormones organize the maturation of inhibitory neurotransmission in the frontal cortex at puberty onset in female mice. Curr Biol 27:1735-1745.e3.

Pitchers KK, Frohmader KS, Vialou V, Mouzon E, Nestler EJ, Lehman MN, Coolen LM (2010) $\Delta$ FosB in the nucleus accumbens is critical for reinforcing effects of sexual reward. Genes Brain Behav 9:831840.

Pitchers KK, Vialou V, Nestler EJ, Laviolette SR, Lehman MN, Coolen LM (2013) Natural and drug rewards act on common neural plasticity mechanisms with $\Delta$ FosB as a key mediator. J Neurosci 33:3434-3442

Robison AJ, Nestler EJ (2011) Transcriptional and epigenetic mechanisms of addiction. Nat Rev Neurosci 12:623-637.

Robison AJ, Vialou V, Mazei-Robison M, Feng J, Kourrich S, Collins M, Wee S, Koob G, Turecki G, Neve R, Thomas M, Nestler EJ (2013) Behavioral and structural responses to chronic cocaine require a feedforward loop involving $\Delta$ FosB and calcium/ calmodulin-dependent protein kinase II in the nucleus accumbens shell. J Neurosci 33:4295-4307.

Sarno E, Robison AJ (2018) Emerging role of viral vectors for circuitspecific gene interrogation and manipulation in rodent brain. Pharmacol Biochem Behav 174:2-8.

Schulz KM, Sisk CL (2006) Pubertal hormones, the adolescent brain, and the maturation of social behaviors: lessons from the Syrian hamster. Mol Cell Endocrinol 254-255:120-126.

Schulz KM, Richardson HN, Zehr JL, Osetek AJ, Menard TA, Sisk CL (2004) Gonadal hormones masculinize and defeminize reproductive behaviors during puberty in the male Syrian hamster. Horm Behav 45:242-249.

Schulz KM, Menard TA, Smith DA, Albers HE, Sisk CL (2006) Testicular hormone exposure during adolescence organizes flankmarking behavior and vasopressin receptor binding in the lateral septum. Horm Behav 50:477-483.

Sesack SR, Grace AA (2010) Cortico-basal ganglia reward network: microcircuitry. Neuropsychopharmacology 35:27-47.

Staffend NA, Hedges VL, Chemel BR, Watts VJ, Meisel RL (2014) Cell-type specific increases in female hamster nucleus accumbens spine density following female sexual experience. Brain Struct Funct 219:2071-2081.

Vertes RP (2006) Interactions among the medial prefrontal cortex, hippocampus and midline thalamus in emotional and cognitive processing in the rat. Neuroscience 142:1-20.

Vialou V, Robison AJ, Laplant QC, Covington HE 3rd, Dietz DM, Ohnishi YN, Mouzon E, Rush AJ 3rd, Watts EL, Wallace DL, Iñiguez SD, Ohnishi $\mathrm{YH}$, Steiner MA, Warren BL, Krishnan V, Bolaños CA, Neve RL, Ghose S, Berton O, Tamminga CA, et al. (2010) DeltaFosB in brain reward circuits mediates resilience to stress and antidepressant responses. Nat Neurosci 13:745-752.

Vialou V, Bagot RC, Cahill ME, Ferguson D, Robison AJ, Dietz DM, Fallon B, Mazei-Robison M, Ku SM, Harrigan E, Winstanley CA, Joshi T, Feng J, Berton O, Nestler EJ (2014) Prefrontal cortical circuit for depression- and anxiety-related behaviors mediated by cholecystokinin: role of $\Delta$ FosB. J Neurosci 34:3878-3887.

Wallace DL, Vialou V, Rios L, Carle-Florence TL, Chakravarty S, Kumar A, Graham DL, Green TA, Kirk A, Iñiguez SD, Perrotti LI, Barrot M, DiLeone RJ, Nestler EJ, Bolaños GC (2008) The influence of DeltaFosB in the nucleus accumbens on natural rewardrelated behavior. J Neurosci 28:10272-10277.

Wassum KM, Izquierdo A (2015) The basolateral amygdala in reward learning and addiction. Neurosci Biobehav Rev 57:271-283.

Zachariou V, Bolanos CA, Selley DE, Theobald D, Cassidy MP, Kelz MB, Shaw-Lutchman T, Berton O, Sim-Selley LJ, Dileone RJ, Kumar A, Nestler EJ (2006) An essential role for DeltaFosB in the nucleus accumbens in morphine action. Nat Neurosci 9:205-211. 